\title{
Seismic reliability analysis of steel moment-resisting frames retrofitted by vertical link elements using combined series-parallel system approach
}

\author{
Vahid Mohsenian $^{1}$ (D) $\cdot$ Iman Hajirasouliha ${ }^{2}$ (D) $\cdot$ Reza Filizadeh $^{3}$ (D)
}

Received: 1 August 2020 / Accepted: 17 November 2020 / Published online: 24 November 2020

(c) The Author(s) 2020

\begin{abstract}
The eccentric bracing system equipped with vertical links is capable of providing high levels of stiffness, strength and ductility, and therefore, can be efficiently used for seismic retrofit of existing structures. This study aims to investigate the seismic reliability of steel moment-resisting frames retrofitted by this system using a novel combined series-parallel system approach. The seismic response of 4, 8 and 12-storey steel moment-resisting frames (MRFs) are evaluated under a set of design basis earthquakes (DBE) before and after retrofitting intervention. Adopting an engineering demand parameter approach (EDP-Based) for reliability assessment and development of analytical models for the frames using systems consisting of the series-parallel elements are the major distinctions between the present study and the other similar works. To estimate the global reliability of the frames, first, the reliability of each storey is individually derived based on various probable damage levels for the lateral-load resisting members. Then, the seismic reliability of the frame is globally obtained by combining the reliability of each storey for different damage levels in the lateral load-resisting subsystems. The results indicate significant impact of this type of bracing system on improvement of the performance level and load-carrying capacity of the frames along with reduction of the lateral displacements. It is shown that application of the vertical links can reduce the maximum inter-storey drifts by at least $60 \%$, while it leads to at most $17 \%$ increase in the base shear. All retrofitted frames exhibited a performance level higher than the Life Safety (LS) when subjected to the DBE hazard level records (earthquakes with return period of 475 years). At the same level of earthquake intensity, in the cases when the drift corresponding to the LS performance level is used as the target, the reliability of the retrofitted frames was improved by more than $90 \%$ compared to the original frames for all damage states developed in the vertical links.
\end{abstract}

Keywords Seismic retrofitting · Eccentric bracing system · Vertical link element · Reliability analysis · Combined series-parallel systems

Vahid Mohsenian

v.mohsenian@usc.ac.ir

Iman Hajirasouliha

i.hajirasouliha@sheffield.ac.uk

Extended author information available on the last page of the article 


\section{Introduction}

Substandard structures with deficient lateral load-carrying systems may exhibit large nonlinear displacements and extensive damage during strong earthquake events. To address this issue, their lateral load-carrying system has to be either modified or retrofitted to provide sufficient energy dissipation capacity and/or lateral strength and stiffness (Shu et al. 2020). In steel structures, addition of concentric (CBF) or eccentric braces (EBF) are one of the viable methods to achieve both improvement in the strength and reduction in the induced displacements (Di Sarno and Elnashai 2009; Mazzolani et al. 2009). When eccentric braces are employed, due to the presence of the yielding fuse, in addition to stiffness the ductility of the system is also enhanced.

In the conventional EBF system, the link beam is horizontal and its longitudinal axis coincides with the storey beam (Engelhardt and Popov 1992). The eccentric bracing system with horizontal link beam is a well-known structural system by the codes and depending on the location of the link (middle or side of the braced span), different specifications are proposed for analysis, modeling and seismic design of this system. Extensive studies have been performed on the seismic performance and design of this type of eccentric bracing system over the past few decades. The need for replacing story beam after severe earthquakes and deformation of the slabs due to link rotations are the main drawbacks of this structural system. To address these issues, several studies have attempted to improve this system by using replaceable link beams (e.g. Mansour et al. 2011; Chesoan et al. 2018; Bozkurt and Topkaya 2018). In an EBF system with horizontal links, the effects of axial forces in the links is considerable and should be included in the seismic design and analysis process (Della Corte et al. 2013; Ji et al. 2015).

The eccentric bracing with vertical shear link can provide a high level of stiffness, strength and ductility in the structural system (see Fig. 1). In this less conventional EBF configuration, the storey beam is continuous and the vertical shear link is attached as an additional element. This structural system was originally developed by Seki et al. (1988) as an efficient technique to resist lateral seismic loads. The stable hysteretic curves and high energy dissipation capacity are counted as the most notable features of this system, leading to satisfactory performance under strong seismic excitations (Baradaran et al. 2015; Bouwkamp et al. 2016; Vetr et al. 2017). Given the fact that vertical links can act as a seismic fuse, the majority of the earthquake energy is absorbed by these elements, and consequently, the other structural members generally remain in their linear phase of behaviour (Zahrai and Mahroozadeh 2010; Mohsenian and Mortezaei 2018a; Mohsenian and Nikkhoo 2019). This implies that, unlike conventional EBF systems, the beam elements and slabs are not affected by the link rotation. The effect of axial forces in the vertical links due to lateral loading of the system is also negligible. Finally, the brace systems with vertical link elements are generally less expensive compared to their equivalent BRB systems, as they do not require a complex manufacturing process and their installation is very simple.

For the seismic design of frame structures with vertical links, Zahrai and Mahroozadeh (2010) proposed response modification factors in the range of 7.15-10.65. Mohsenian and Mortezaei (2018b) also used a multi-level approach to determine the response modification factor for eccentric braced frames with vertical links. It was shown that using a response modification factor equal to 8 generally leads to desirable seismic performance even under high seismic hazard levels.

Daryan et al. (2008) showed that using vertical links with mild steel can prevent the local buckling of the links and lead to higher energy dissipation capacity and ductility 


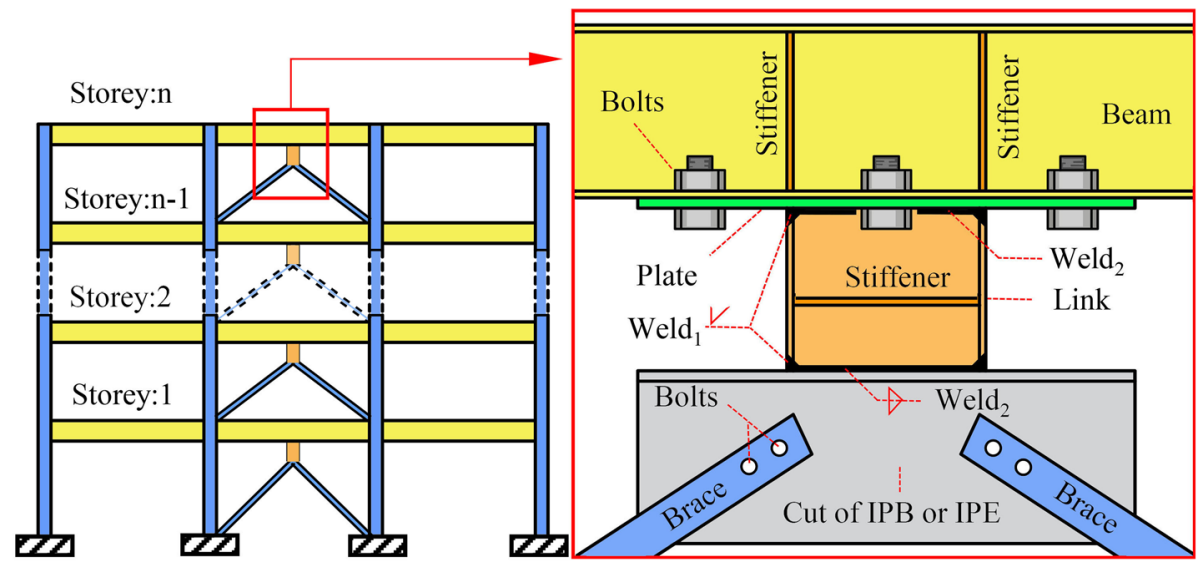

Fig. 1 Eccentric braced frame equipped with vertical link beam and schematic details of the link connection

of the system. In another relevant study, Lian and Su (2017) performed experimental and numerical investigation on the performance of eccentric braced frames with vertical links made of two different steel grades. The results of their study indicated that utilizing high strength steel for the frame elements provides wider hysteresis curves (without significant strength loss), high energy dissipation and acceptable load bearing capacity.

Shayanfar et al. (2011) showed that using web stiffeners can considerably improve the shear capacity and ductility of the vertical link elements. Zahrai and Moslehi Tabar (2013) also estimated the hysteresis damping and plastic rotation of the shear links to be around $30 \%$ and 0.15 rad, respectively. In another study, Zaharai and Parsa (2015) concluded that a reduction in the width of the beam flange does not deteriorate the stability of hysteresis curves and the energy absorption capacity of the system, as long as sufficient connections are provided for the vertical links.

Bouwkamp et al. (2016) and Vetr et al. (2017) studied the seismic performance of eccentric braced frames equipped with vertical links and proposed simple equations to design the link elements. By conducting experimental tests on eccentric braced frames equipped with vertical links, Duan and Su (2017) demonstrated that shorter links with dominant shear behaviour provide higher ductility and energy dissipation capacity compared to the flexural deformable links. Similarly, Mohsenian et al. (2021) showed the efficiency of these structural systems under sequential earthquakes. In another relevant study, Mohsenian et al. 2020a demonstrated that the seismic performance of low to medium rise steel moment resisting frames can be considerably improved by using vertical link elements. Rahnavard et al. (2017) and Mohsenian and Nikkhoo (2019) also showed that using dual vertical links can considerably increase the energy absorption and shear capacity of eccentrically steel braced frames.

Although the efficiency of eccentric bracing systems with vertical links for seismic retrofitting of existing structures has been widely investigates, there is a gap of knowledge in seismic design and reliability assessment of these systems. Unlike conventional eccentric bracing systems with horizontal link beams, current seismic design guidelines do not provide any specific design regulations for the eccentric bracing system with vertical link elements. In this study, the design process of eccentric bracing systems equipped with vertical links is first explained. Subsequently, a novel combined series-parallel system approach 
is adopted for seismic reliability assessment of 4, 8 and 12-storey steel moment-resisting frames (MRFs) retrofitted by using vertical links under a set of spectrum compatible earthquake records. The results highlight the capabilities of this bracing system to reduce the displacement demands and promote the seismic reliability of MRFs under different seismic hazard levels.

\section{Specifications of the studied models}

In order to study the impact of vertical links on the seismic performance of structures, 4,8 and 12-storey steel moment-resisting frames shown in Fig. 2 are considered. As illustrated in this figure, in terms of geometry and distribution of the dead and live loads $\left(Q_{D}\right.$ and $\left.Q_{L}\right)$, all frames are symmetric in the " $\mathrm{z}$ " direction. The length and height of bays and storeys are respectively equal to 5 and $3.2 \mathrm{~m}$.

The studied structures are residential buildings (medium importance) designed according to the ANSI/AISC 360-10 using ETABS software (CSI 2015). To ensure the structures represent substandard systems (i.e. require rehabilitation), the maximum peak ground acceleration (PGA) of $0.15 \mathrm{~g}$ is used in the design process, which is less than $50 \%$ of the Iranian Seismic Design Code (ISCP 2014) design acceleration of $0.35 \mathrm{~g}$.

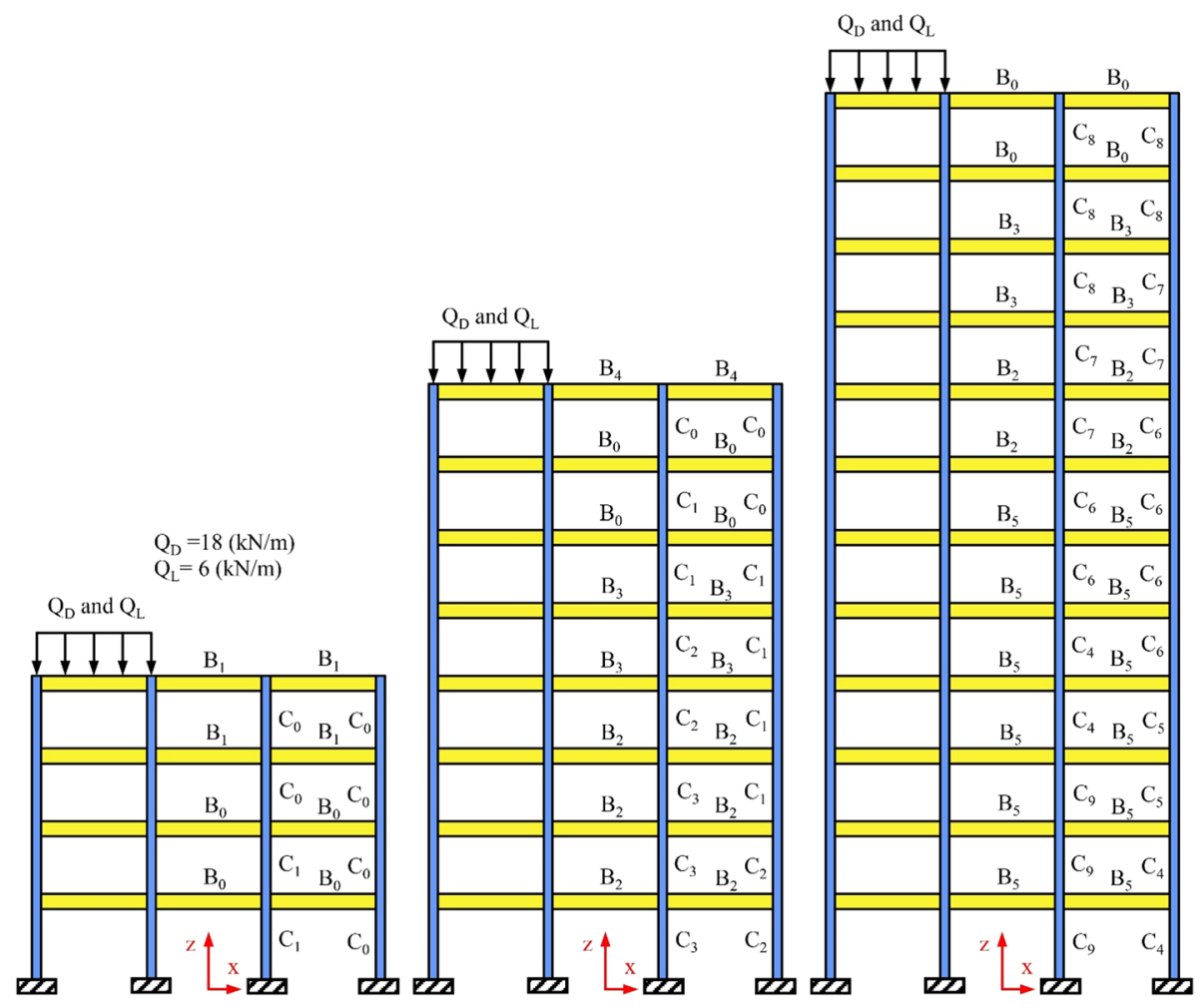

Fig. 2 Geometric characteristics and gravity loading of the moment-resisting frames to be retrofitted 
Table 1 Specifications of the sections designed for the I-section beams and SHS columns (units: $\mathrm{mm}$ )

\begin{tabular}{lllll}
\hline Columns & & & \multicolumn{2}{l}{ Beams } \\
\cline { 1 - 2 } \cline { 5 - 5 } ID & Section $(B, t)$ & & ID & Section $\left(\mathrm{H}_{\mathrm{w}}, \mathrm{t}_{\mathrm{w}}\right)-\left(\mathrm{B}_{\mathrm{f}}, \mathrm{t}_{\mathrm{f}}\right)$ \\
\hline $\mathrm{C}_{0}$ & 180.10 & & $\mathrm{~B}_{0}$ & $200,8-150,12$ \\
$\mathrm{C}_{1}$ & 200.10 & & $\mathrm{~B}_{1}$ & $200,8-150,10$ \\
$\mathrm{C}_{2}$ & 250.10 & & $\mathrm{~B}_{2}$ & $240,8-150,12$ \\
$\mathrm{C}_{3}$ & 300.10 & & $\mathrm{~B}_{3}$ & $220,8-150,12$ \\
$\mathrm{C}_{4}$ & 300.12 & & $\mathrm{~B}_{4}$ & $180,8-150,10$ \\
$\mathrm{C}_{5}$ & 270.12 & & $\mathrm{~B}_{5}$ & $270,8-150,12$ \\
$\mathrm{C}_{6}$ & 240.12 & & - & - \\
$\mathrm{C}_{7}$ & 200.12 & & - & - \\
$\mathrm{C}_{8}$ & 180.12 & & - & - \\
$\mathrm{C}_{9}$ & 350.12 & - & - \\
\hline
\end{tabular}

Fig. 3 Geometrical properties of the sections considered for beams and columns

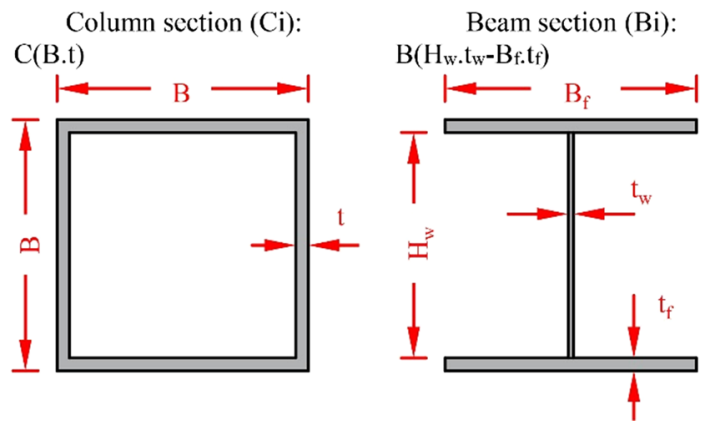

The buildings are residential constructed in a site with high seismicity. Based on the soil classification provided by the Iranian Seismic Code of Practice (ISCP 2014), the structures are founded on the soil type II (stiff soil whit shear wave velocity ranging between 375 and $750 \mathrm{~m} / \mathrm{s}$ (ASCE 2010)). Dimensions of the beams $\left(B_{i}\right)$ and columns $\left(C_{i}\right)$ at each storey level are given in Table 1. Square hollow section (SHS) and I-section elements are used for the columns and beams, respectively (see Fig. 3). The effect of rigid diaphragm is considered in the modelling by constraining the horizontal displacements at each storey level. A36 steel is considered with yielding stress and Poisson's ratio of $250 \mathrm{MPa}$ and 0.26 , respectively (ASTM 2019). 


\section{Nonlinear modeling and determination of the strength and deformation parameters}

PERFORM-3D (CSI 2017) was used to model the structures and conduct the nonlinear analyses. In order to define the behaviour of beams and columns, the generalized loaddisplacement curve shown in Fig. 4 has been utilized. The parameters a, b and c in this figure are extracted from the tables of modeling and acceptance criteria of nonlinear methods for steel members in accordance with ASCE/SEI41-17. The maximum expected strength $\left(\mathrm{Q}_{\mathrm{CE}}\right)$ for the beams is derived from Eq. 1. For the columns, depending on the axial force level, the maximum expected strength is derived from Eq. 2 or 3 . In these relations, the parameters $\mathrm{Z}$ and $\mathrm{F}_{\mathrm{ye}}$ are the plastic section modulus and the expected yield strength of the materials. $\mathrm{P}$ is axial force of the element in the beginning of the dynamic analysis and $\mathrm{P}_{\mathrm{ye}}$ is the axial force corresponding to the expected yield of the element which is derived from multiplication of the element cross section (A) by the expected yield strength of the mate$\operatorname{rial}\left(\mathrm{P}_{\mathrm{ye}}=\mathrm{A} . \mathrm{F}_{\mathrm{ye}}\right)$.

$$
\begin{gathered}
Q_{C E}=Z F_{y e} \\
Q_{C E}=Z F_{y e}\left(1-\frac{|P|}{2 P_{y e}}\right) \text { for }\left(\frac{|P|}{P_{y e}}<0.2\right) \\
Q_{C E}=Z F_{y e} \frac{9}{8}\left(1-\frac{|P|}{P_{y e}}\right) \text { for } \quad\left(\frac{|P|}{P_{y e}} \geq 0.2\right)
\end{gathered}
$$

To take into account the non-linear behaviour of the frame elements, moment and axialmoment interaction hinges were assigned to the both ends of the beam and column elements, respectively. A constant damping ratio of 5\% was assigned to the frames using the Rayleigh damping model. P-Delta effects were also considered in the analyses.

\subsection{Vertical links}

The vertical links are designed in such a way that they start yielding earlier than the other members. As mentioned before, these elements are meant to act as the sacrificial fuses

Fig. 4 Load-displacement curve used for the beams and columns based on ASCE/SEI41-17 (2017)

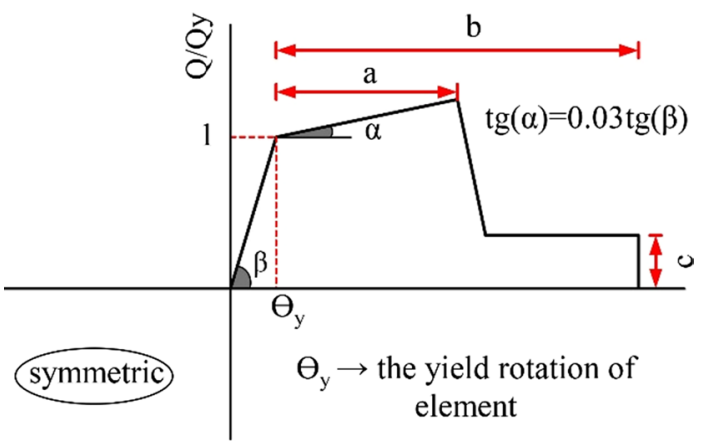


under the DBE hazard intensity. Figure 5 illustrates the force distribution in moment resisting frames with vertical shear links.

Assuming shear yielding of the vertical links, the required web area in each storey $\left(A_{w}\right)$ is derived by substituting storey shear $\left(\mathrm{F}_{\mathrm{i}}\right)$ in the relation of section plastic shear capacity $\left(\mathrm{V}_{\mathrm{p}}\right)$ (Eq. 4). To ensure the shear links act as an earthquake fuse, this shear storey should be less than the lateral design loads corresponding to the DBE hazard level (here $50 \%$ of the loads are used). Having $\mathrm{A}_{\mathrm{w}}$, a steel profile is obtained for the link element by considering the geometrical condition of the link and constructional constraints. To facilitate the construction process, generally only a few types of links are utilized in the height of the structure. Therefore, it is necessary to check the shear yielding of the link element after the initial design. For this purpose, the plastic moment capacity $\left(\mathrm{M}_{\mathrm{p}}\right)$ and plastic shear resistance $\left(\mathrm{V}_{\mathrm{p}}\right)$ of the selected profiles are calculated using Eqs. 4 and 5, respectively.

$$
\begin{gathered}
\mathrm{M}_{\mathrm{P}}=\mathrm{Z} \cdot \mathrm{F}_{\mathrm{ye}} \\
\mathrm{V}_{\mathrm{P}}=0.6 \mathrm{~F}_{\mathrm{ye}} \cdot \mathrm{A}_{\mathrm{w}}
\end{gathered}
$$

In these Equations, $\mathrm{Z}, \mathrm{F}_{\mathrm{ye}}$ and $\mathrm{A}_{\mathrm{w}}$ denote the plastic section modulus, expected yield strength and cross-sectional area of the web (excluding the thickness of flanges), respectively.

Based on the equilibrium equation of the link (in the case that bending moments at the two ends of the beam are of the same values) and to ensure occurrence of shear yielding, the length of the link beam will be given as in Eq. (6) (ASCE/SEI41-17):

$$
\mathrm{e} \leq 1.6 \mathrm{Mp} / \mathrm{Vp}
$$

In some cases, to achieve a more conservative relationship, the length of the link beam is proposed based on Eq. (7) (Kasai and Popov 1986; Vetr 1998):

$$
\mathrm{e} \leq 1.4 \mathrm{Mp} / \mathrm{Vp}
$$

In the cases when the end bending moments are unequal, considering the parameter $\mathrm{k}$ as the ratio of the bottom to the top moments $\left(k=\mathrm{M}_{2} / \mathrm{M}_{1}\right)$, accounting for the effect of strain hardening similar to the horizontal links, Eq. (8) can be used to calculate the length of the vertical link.

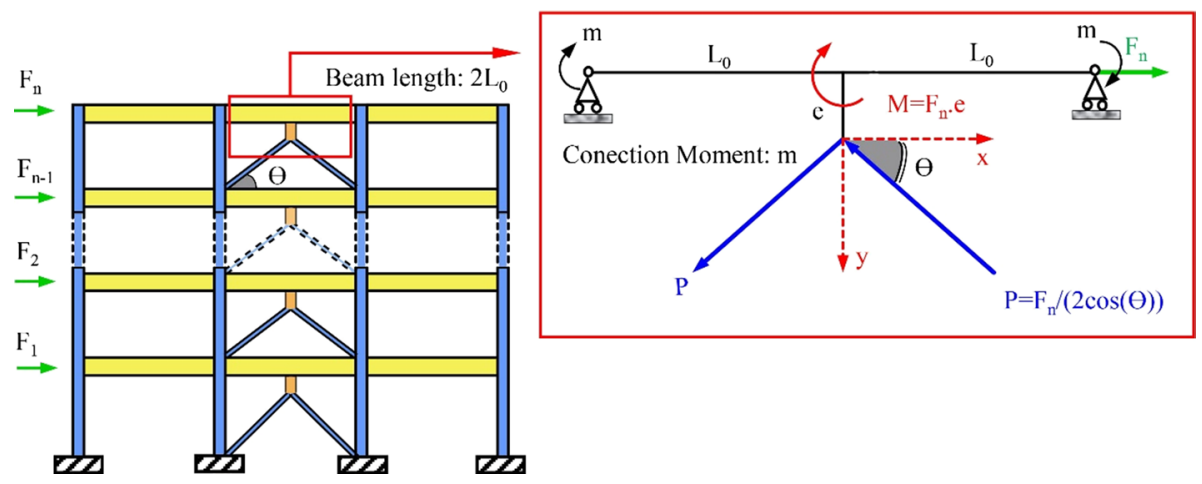

Fig. 5 Force distribution in moment resisting frames with vertical shear links 


$$
\mathrm{e} \leq 0.8(1+\mathrm{k}) \mathrm{Mp} / \mathrm{Vp}
$$

It is of note that for the shear links used in this study, the value of $k$ will be equal to zero. For such cases, to obtain more conservative results, the equation for the length of the shear link can be written as follows (Shayanfar et al. 2011).

$$
\mathrm{e} \leq 0.7 \mathrm{Mp} / \mathrm{Vp}
$$

In this study, the length of the link was set equal to $200 \mathrm{~mm}$ to ensure shear yielding occurs before damage to the other elements by satisfying the above equations (Sabouri-Ghomi and Saadati 2014; Duan and Su 2017). Consequently, the expected shear strength of the link was taken into account to define the nonlinear capacity curve of these elements.

According to Fig. 6, for the purpose of retrofitting, the eccentric bracing system with vertical links has been placed in the middle bays of the MRFs. The sections designed for the vertical links and brace elements are shown in Fig. 6, and their properties are presented in Table 2.

Based on the end conditions defined for the vertical links (these elements are working as cantilevers), stiffness of each link $\left(\mathrm{k}_{\mathrm{e}}\right)$ is calculated using Eq. (10).

$$
k_{e}=\frac{k_{s} \cdot k_{b}}{k_{s}+k_{b}}
$$

where $\mathrm{k}_{\mathrm{b}}$ and $\mathrm{k}_{\mathrm{s}}$ represent the flexural and shear stiffness of the element, respectively, and are obtained using the following equations:

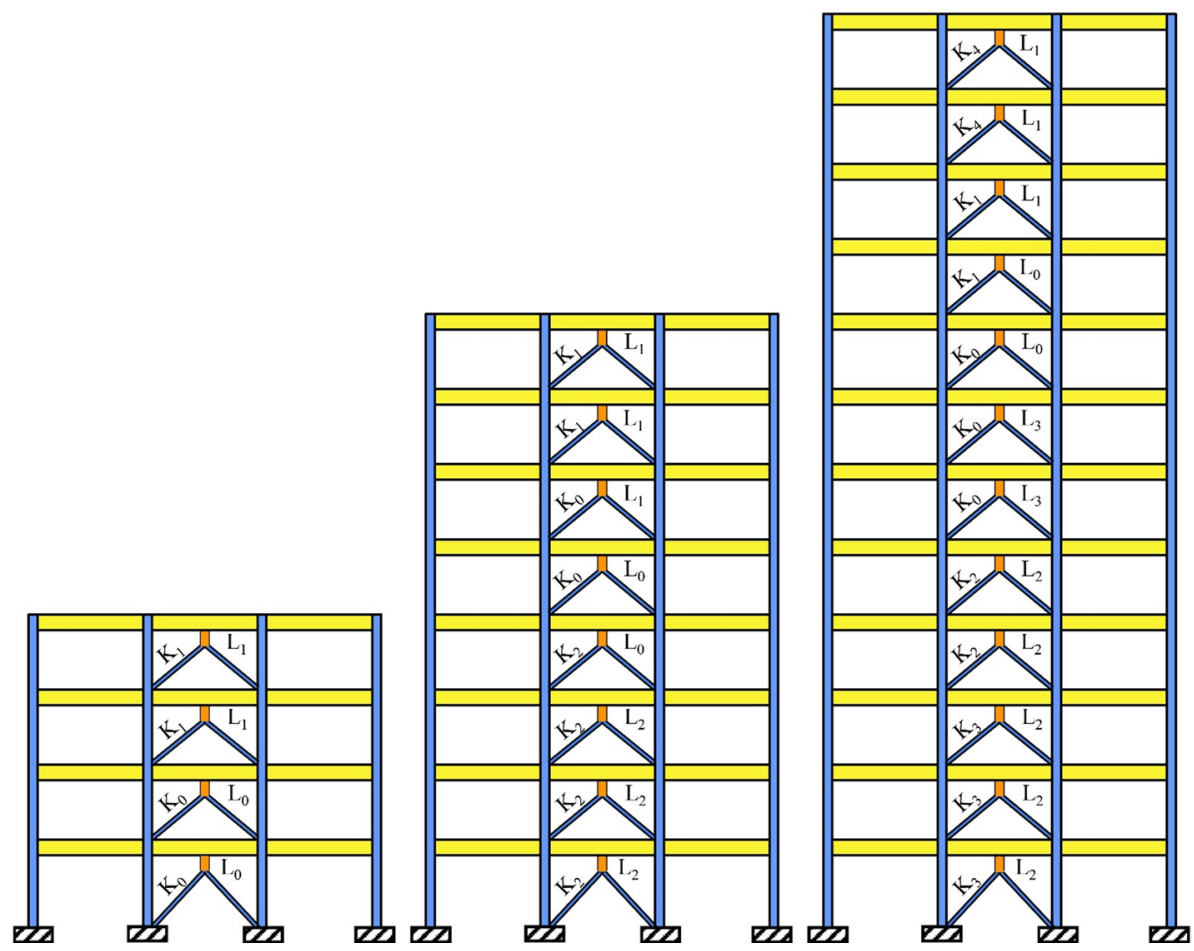

Fig. 6 Layout of the braces and vertical links in the designed moment-resisting frames 
Table 2 Specifications of the sections designed for the braces and vertical links (units: $\mathrm{mm}$ )

\begin{tabular}{lllll}
\hline Links & & & \multicolumn{2}{l}{ Braces } \\
\cline { 5 - 5 } \cline { 5 - 5 } ID & Section & & ID & Section \\
\hline $\mathrm{L}_{0}$ & IPE200 & & $\mathrm{K}_{0}$ & 2UPN120 \\
$\mathrm{L}_{1}$ & IPE160 & & $\mathrm{K}_{1}$ & 2UPN100 \\
$\mathrm{L}_{2}$ & IPE240 & & $\mathrm{K}_{2}$ & 2UPN140 \\
$\mathrm{L}_{3}$ & IPE220 & & $\mathrm{K}_{3}$ & 2UPN160 \\
- & - & $\mathrm{K}_{4}$ & 2UPN80 \\
\hline
\end{tabular}

$$
\begin{aligned}
& k_{s}=\frac{G \cdot A_{w}}{e} \\
& k_{b}=\frac{3 E \cdot I_{b}}{e^{3}}
\end{aligned}
$$

where $I_{b}, E$ and $G$ stand for the moment of inertia, elastic and shear moduli of the link, respectively. The above equations are utilized to assess the adequacy of the selected section and length of the link element to control the storey drifts.

The designed vertical link elements are modeled in ABAQUS (2014). The capacity curves are then extracted for the links under cyclic loading. Subsequently, as shown in Fig. 7, the derived capacity curves are idealized as multi-linear curves to be used in PERFORM-3D software.

It should be mentioned that the shear capacity of the sections obtained from ABAQUS were in an acceptable agreement with those derived from Eq. (5). Also as observed in Fig. 8, the level of stress in flanges is always lower than that of the web validating the numerical modeling of the vertical links and assumption of their shear yielding.

The shear strain angle of the link $(\gamma)$ is one of the other key parameters for design purposes. Thereby, first, the load-displacement curve of the link elements is constructed using detailed FE models and then, in accordance with Fig. 8 and based on the maximum stress value, four different limit states are designated for $\gamma$. To simulate the more realistic
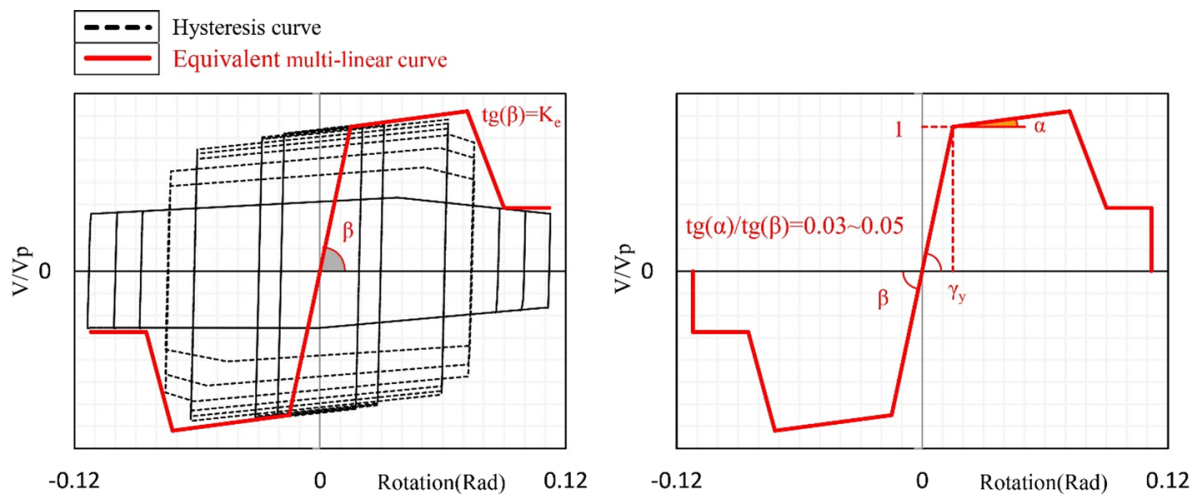

Fig. 7 A sample of the extracted hysteretic response curves for the vertical links and its idealized multilinear equivalent 


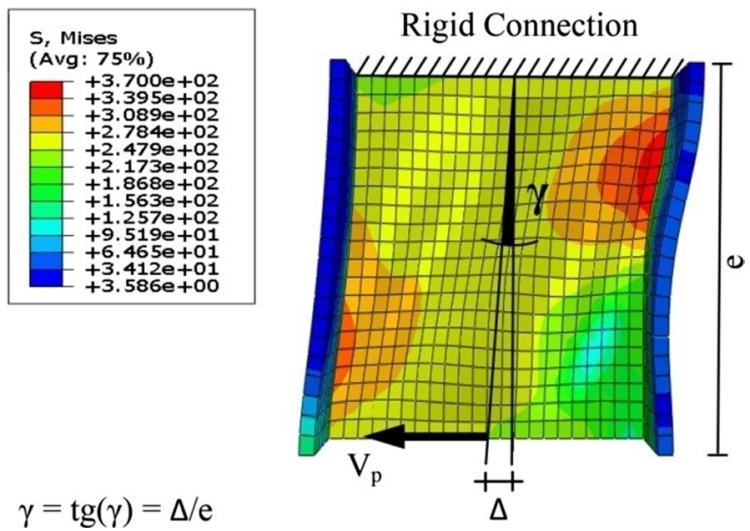

Damage States:

\begin{tabular}{cccc}
\hline$(1)$ & $(2)$ & $(3)$ & $(4)$ \\
\hline$\gamma_{1}=\gamma_{\mathrm{y}}=0.0024(\mathrm{rad})$ & $\gamma_{2}=0.05(\mathrm{rad})$ & $\gamma_{3}=0.08(\mathrm{rad})$ & $\gamma_{4}=0.1(\mathrm{rad})$ \\
\hline $\mathrm{f}_{\mathrm{y}}=250$ & $\mathrm{f}_{\mathrm{y}}<\sigma<\mathrm{f}_{\mathrm{u}}$ & $\mathrm{f}_{\mathrm{y}}<\sigma<\mathrm{f}_{\mathrm{u}}$ & $\mathrm{f}_{\mathrm{u}}=400$ \\
\hline
\end{tabular}

Fig. 8 Deformation and stress level in the Limit States considered for the link elements at $\gamma=0.1 \mathrm{rad}$ (Stresses are in MPa)

behaviour of the shear link in FE modelling, the boundary condition at one side of the element is rigid (connection to the beam) and the other side is free to rotate but constraint in the horizontal direction (connection to the brace elements). The main reason for the deformed shape of the right flange in Fig. 8 is due to the local buckling of the web adjacent to the flange at the ultimate point $(\gamma=0.1 \mathrm{rad})$.

Based on the previous experimental and analytical studies (Zahrai and Mahroozadeh 2010; Zahrai and Moslehi Tabar 2013), shear strain angle generally ranges between $0.128^{\mathrm{rad}}$ and $0.156^{\mathrm{rad}}$ prior to the occurrence of fracture. To provide safe design solutions in this study, maximum shear strain angle has been limited to $0.1^{\mathrm{rad}}$ (the strain corresponding to occurrence of the ultimate stress $\left(f_{u}\right)$ for the first time) in the event of DBE.

As explained earlier, the link elements are designed to yield under the seismic loads earlier than the other members. Hence, the yield shear strain angle $\left(\gamma_{\mathrm{y}}\right)$ represents a major state taken as the lower bound for the strain angle of the links. According to Fig. $8,\left(\gamma_{\mathrm{y}}\right)$ is calculated using Eq. (13).

$$
\gamma_{y}=\frac{V_{p}}{k_{e} \cdot e}
$$

To numerically model the vertical links, the "column" element with linear behaviour and concentrated "shear" hinge has been employed.

\subsection{Braces}

The brace elements were designed based on the maximum shear capacity of the vertical links. To achieve this, by assuming the plastic shear capacity of the link (Vp) as the storey shear, the brace forces are derived by establishing equilibrium equation (see Fig. 5). After determining the maximum brace forces, their cross-section area is determined such that the 
buckling of the braces is prevented before yielding of the links. The required sections for the braces are shown in Fig. 6, while their specifications are presented in Table 2.

It should be mentioned that the adopted retrofitting method can increase axial forces in the columns adjacent to the brace elements. Therefore, the final step is to control the interaction of axial force and bending moments in the columns and the necessity of local strengthening. However, since vertical shear links act as earthquake fuses, these additional imposed loads are considerably lower compared to the case that conventional concentric or eccentric braces are utilized.

As simple connections are used at both ends of the braces, the earthquake-induced energy is absorbed in the braces through formation of the axial hinges. The axial deformations caused by the expected buckling and tensile loads $\left(\Delta_{\mathrm{c}}\right.$ and $\left.\Delta_{\mathrm{t}}\right)$ corresponding to the yielding limit state are taken as the criteria for ductility and nonlinear behaviour (ASCE/ SEI41-17). Accordingly, the axial deformation $(\Delta)$ of these elements has been calculated based on Eq. (14).

$$
\Delta=\mathrm{FL} / \mathrm{EA}
$$

where $\mathrm{E}, \mathrm{A}$ and $\mathrm{L}$ denote the elastic modulus, cross-sectional area and free length of the brace members, respectively. By replacing $(\mathrm{F})$ with the expected strength of the brace under tension $\left(\mathrm{T}_{\mathrm{CE}}\right)$ and considering the lower limit of strength under compression $\left(\mathrm{P}_{\mathrm{CL}}\right)$, the $\left(\Delta_{\mathrm{t}}\right)$ and $\left(\Delta_{\mathrm{c}}\right)$ parameters can be calculated, respectively.

The generalized load-displacement curve adopted for the modelling of the brace elements in tension and compression is depicted in Fig. 9. The required parameters for nonlinear modeling of the braces (coupled channel profile, herein) and their acceptance criteria for different performance levels are chosen based on ASCE/SEI41-17. The "bar" element PERFORM-3D (CSI 2017) has been utilized for modeling the braces as such elements can only resist the axial forces.

The other assumptions made in this study include 2D behaviour for the frames, rigid connection of the columns to the base and ignoring the foundation uplift.

During both phases of linear and nonlinear analysis, the same assumptions have been made for gravity loading on the frames. In the load combination incorporating gravity and lateral loads, the upper limit of the gravity load effects has been considered as in Eq. (15) (ASCE/SEI41-17).

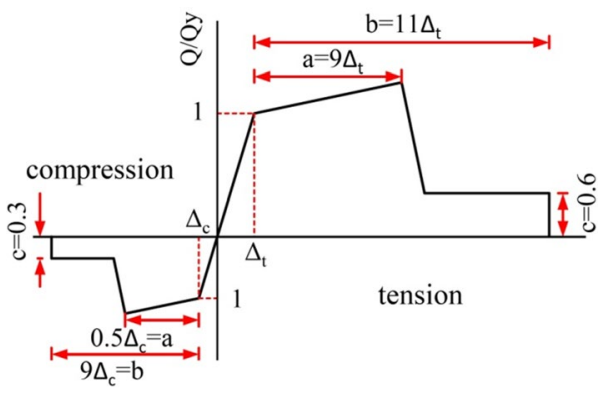

\begin{tabular}{lccc}
\hline \multicolumn{1}{c}{ Performance Levels $\rightarrow$} & IO & LS & CP \\
\hline Compression: & $\Delta=0.5 \Delta \mathrm{c}$ & $\Delta=7 \Delta \mathrm{c}$ & $\Delta=9 \Delta \mathrm{c}$ \\
\hline Tension: & $\Delta=0.5 \Delta \mathrm{t}$ & $\Delta=8 \Delta \mathrm{t}$ & $\Delta=11 \Delta \mathrm{t}$ \\
\hline
\end{tabular}

Fig. 9 Load-displacement curve adopted for the modelling of the brace elements in tension and compression and their acceptance criteria based on ASCE/SEI41-17 


$$
\mathrm{Q}_{\mathrm{g}}=\mathrm{Q}_{\mathrm{D}}+0.25 \mathrm{Q}_{\mathrm{L}}
$$

In this equation, $Q_{D}$ and $Q_{L}$ are, respectively, the actions caused by dead and live loads (see Fig. 2).

\section{Multi modal dynamic analysis}

The results of the Eigen-value analysis on the structures before and after retrofitting are given in Table 3. The comparison between the results indicates the remarkable impact of the vertical links on the modal characteristics of the frames. As it can be seen, application of the proposed retrofitting technique, has managed to reduce the period of vibration in the first translational mode by $59 \%, 49.3 \%$ and $55.4 \%$ in 4,8 and 12 -storey frames, respectively. On this basis, it can be concluded that this technique is capable of significantly increasing the lateral stiffness of the structures. After retrofitting, the effective translational mass ratio of the first mode has also increased in all the three structures. It should be noted that for the structures with fundamental period shorter than 1 and the effective translational mass ratio greater than $75 \%$ in the first mode of vibration, the assumption of triangular distribution of seismic loads along the height for static and push-over analyses is generally accepted.

\section{Time-history analysis}

Since the aim of this research is to evaluate the seismic performance of the structures under the code's design basis earthquake and in order to minimize discrepancy of the results and achieve more consistency between the utilized ground motions with the site conditions, artificial records corresponding to the demand design spectrum of the site are utilized. Accordingly, 12 artificial accelerograms are developed based on demand spectrum of the site for soil type II (with shear wave velocity between 375 and $750 \mathrm{~m} / \mathrm{s}$ ) and hazard level I (return period of 475 year) according to Iran's seismic design standard (ISCP 2014), using wavelet transformation method (Hancock et al. 2006). The main components of the earthquakes listed in Table 4 are used for producing the artificial accelerograms. These far-fault earthquake records are extracted from the database of PEER website (http://peer.berkeley. edu/peer-ground-motion-database) based on the selected site condition.

As shown in Fig. 10, there is a good agreement between the response spectra of the produced artificial records and the demand spectrum with the peak ground acceleration

Table 3 Vibration period (T) and translational effective mass factors (M) before and after retrofitting

\begin{tabular}{|c|c|c|c|c|c|c|c|c|c|c|c|c|}
\hline \multirow[t]{3}{*}{ Mode no. } & \multicolumn{4}{|c|}{ 4-storey frame } & \multicolumn{4}{|c|}{ 8-storey frame } & \multicolumn{4}{|c|}{ 12-storey frame } \\
\hline & \multicolumn{2}{|c|}{ Original } & \multicolumn{2}{|c|}{ Retrofitted } & \multicolumn{2}{|c|}{ Original } & \multicolumn{2}{|c|}{ Retrofitted } & \multicolumn{2}{|c|}{ Original } & \multicolumn{2}{|c|}{ Retrofitted } \\
\hline & $\mathrm{T}(\mathrm{s})$ & $\mathrm{M}(\%)$ & $\mathrm{T}(\mathrm{s})$ & $\mathrm{M}(\%)$ & $\mathrm{T}(\mathrm{s})$ & $\mathrm{M}(\%)$ & $\mathrm{T}(\mathrm{s})$ & $\mathrm{M}(\%)$ & $\mathrm{T}(\mathrm{s})$ & $\mathrm{M}(\%)$ & $\mathrm{T}(\mathrm{s})$ & $\mathrm{M}(\%)$ \\
\hline 1 & 1.34 & 82.27 & 0.55 & 85.50 & 2.07 & 76.63 & 1.05 & 78.30 & 2.71 & 68.58 & 1.21 & 74.47 \\
\hline 2 & 0.44 & 12.26 & 0.19 & 11.16 & 0.73 & 12.02 & 0.35 & 13.74 & 0.99 & 19.46 & 0.38 & 12.50 \\
\hline 3 & 0.23 & 3.96 & 0.11 & 2.53 & 0.41 & 4.64 & 0.20 & 3.86 & 0.57 & 5.74 & 0.20 & 4.38 \\
\hline
\end{tabular}




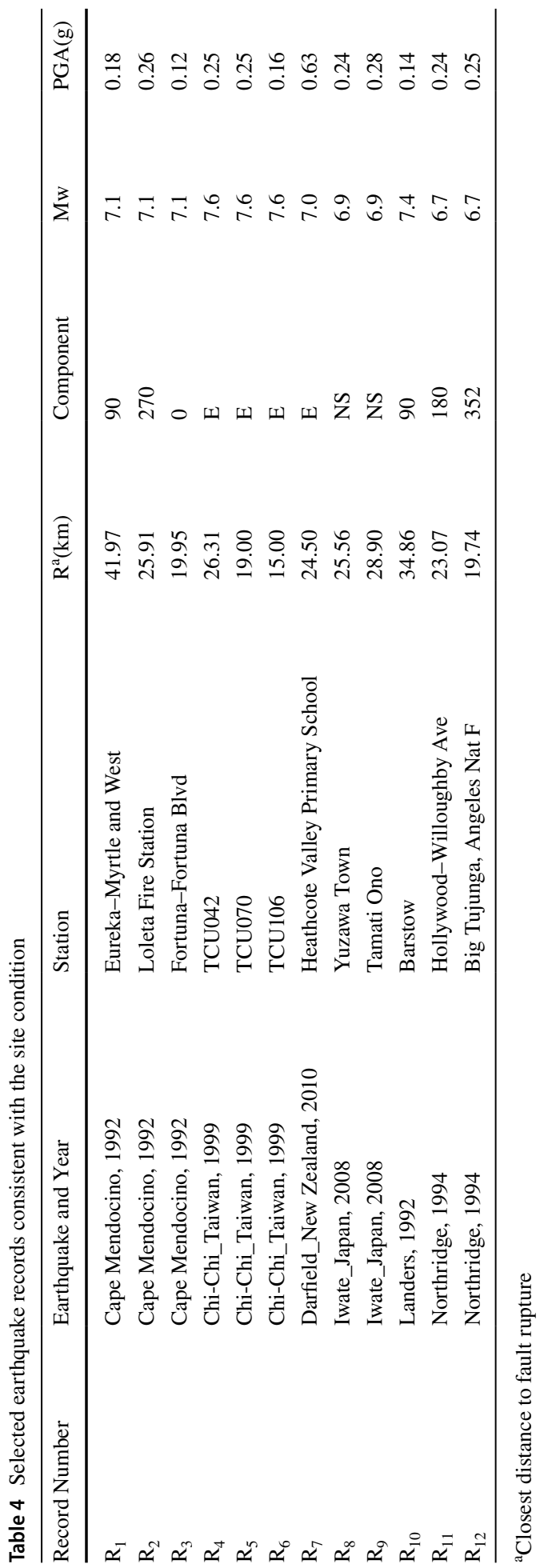




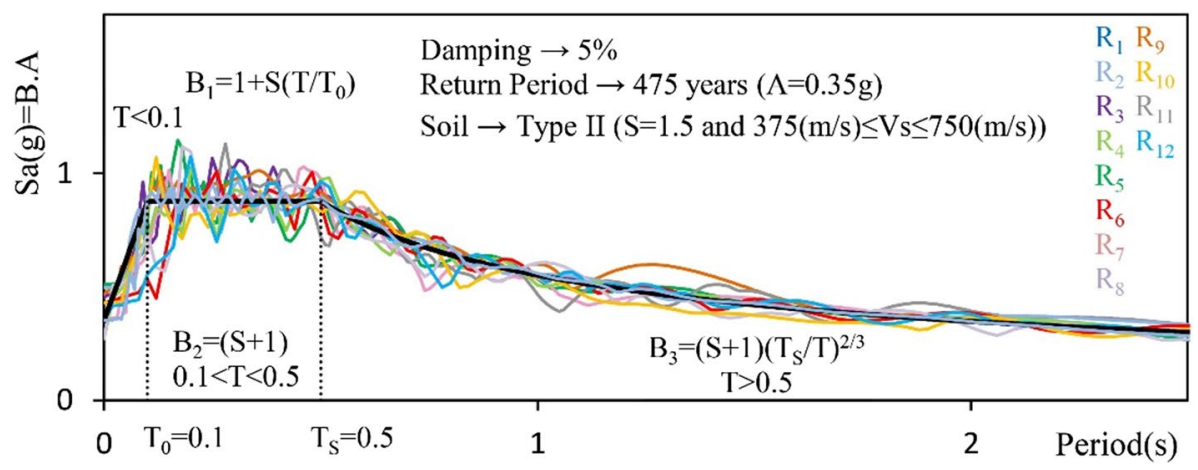

Fig. 10 Comparison between spectrum of the principal components of the selected earthquakes $\left(\mathrm{R}_{\mathrm{i}}\right)$ and the demand spectrum

Table 5 Rate of energy dissipated by different members before and after the retrofitting under $\mathrm{R}_{5}(\%)$

\begin{tabular}{|c|c|c|c|c|c|c|}
\hline \multirow{2}{*}{$\begin{array}{l}\text { Frames } \rightarrow \\
\text { Conditions } \rightarrow\end{array}$} & \multicolumn{2}{|c|}{ 4-Storey frame } & \multicolumn{2}{|c|}{ 8-Storey frame } & \multicolumn{2}{|c|}{ 12-Storey frame } \\
\hline & Original & Retrofitted & Original & Retrofitted & Original & Retrofitted \\
\hline Total energy (kj) & $14.56 \times 10^{3}$ & $4.75 \times 10^{3}$ & $22.88 \times 10^{3}$ & $22.02 \times 10^{3}$ & $36.05 \times 10^{3}$ & $41.69 \times 10^{3}$ \\
\hline $\begin{array}{l}\text { Dissipated energy in } \\
\text { all elements }(\mathrm{kj})\end{array}$ & $5.41 \times 10^{3}$ & $3.15 \times 10^{3}$ & $11.76 \times 10^{3}$ & $14.76 \times 10^{3}$ & $16.79 \times 10^{3}$ & $27.72 \times 10^{3}$ \\
\hline Columns & $35.8 \%$ & $0.0 \%$ & $27.0 \%$ & $0.0 \%$ & $12.0 \%$ & $0.0 \%$ \\
\hline Beams & $64.2 \%$ & $1.8 \%$ & $73.0 \%$ & $6.7 \%$ & $88.0 \%$ & $3.6 \%$ \\
\hline Links & - & $98.2 \%$ & - & $93.3 \%$ & - & $96.4 \%$ \\
\hline Braces & - & $0.0 \%$ & - & $0.0 \%$ & - & $0.0 \%$ \\
\hline
\end{tabular}

of $0.35 \mathrm{~g}$. Therefore, the produced records can be practically used as demand earthquakes. These spectrum-compatible records are applied to both the original bare frames and the retrofitted structures.

Under each artificial accelerogram, the rate of energy dissipated by different groups of load-carrying members before and after the retrofitting intervention were obtained. As an example, Table 5 shows the results for the $\mathrm{R}_{5}$ record.

The obtained results show that after retrofitting intervention, a major part of the earthquake input energy is dissipated by the vertical links. It means that the damages mainly concentrate in the links, and therefore, other structural elements (columns and braces) remain in the elastic range of behavior or exhibit low damage levels under the design earthquake intensity level.

Subsequently, under each artificial accelerogram, maximum shear forces and interstorey drifts (for both original and retrofitted frames) were obtained and their mean values were taken as the criterion to comparatively analyze the results (see Figs. 11 and 12). In addition, for better comparison, the variations of these parameters caused by retrofitting intervention are given in Table 6. In this table, "-" and "+" signs demonstrate if the parameters have decreased or increased. To study the effectiveness of the proposed retrofitting approach on improvement of the performance level of the frames, maximum drifts of 0.7 and $2.5 \%$ were respectively considered as the values 

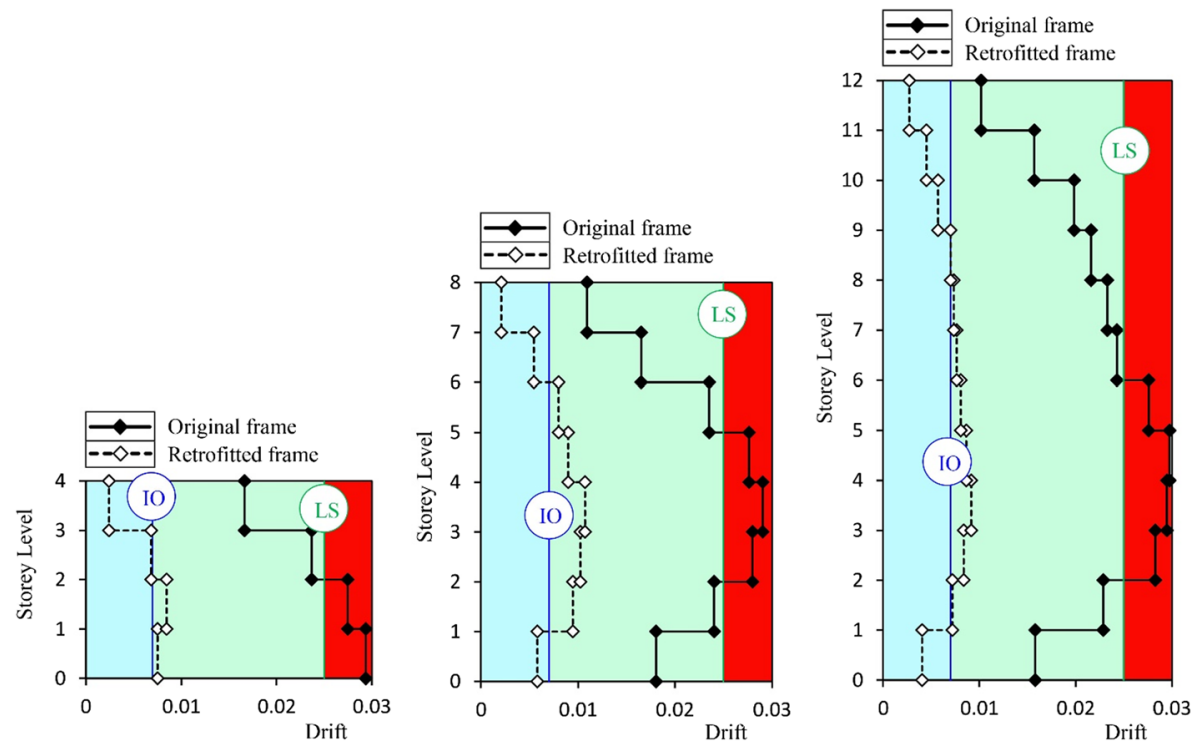

Fig. 11 Mean value of the maximum drifts under the DBE hazard level before and after the retrofitting
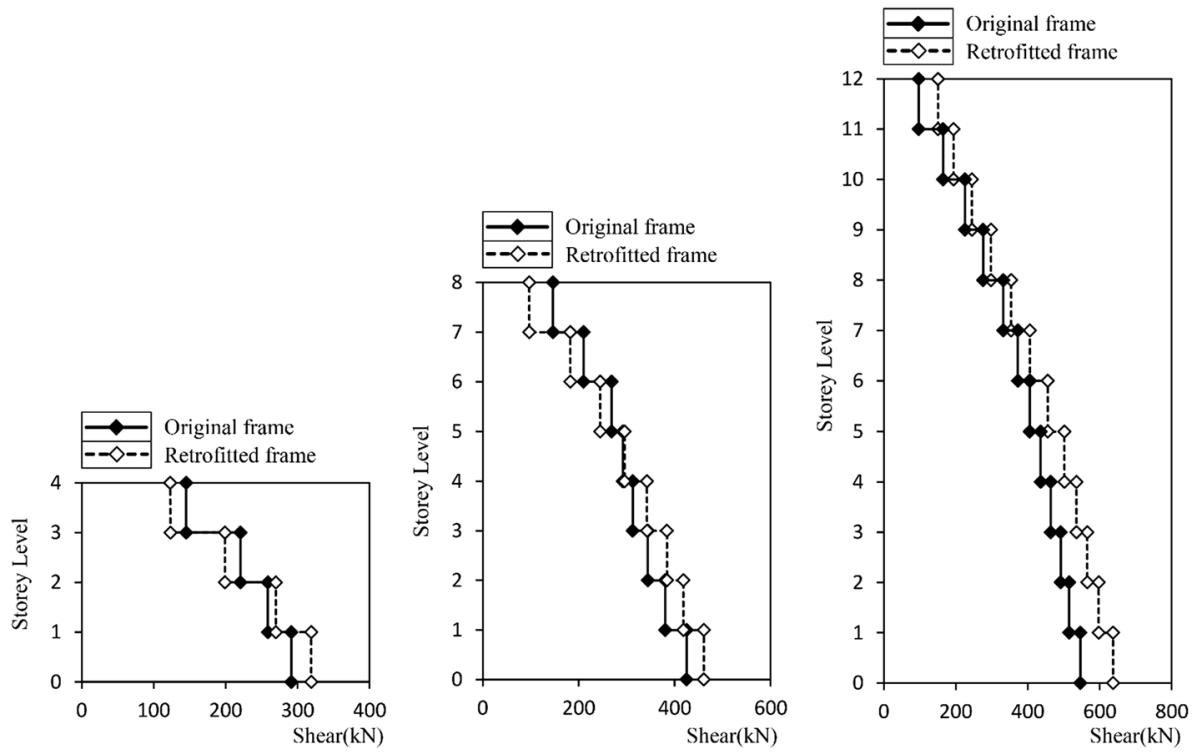

Fig. 12 Mean value of the maximum storey shear forces under the DBE hazard level before and after the retrofitting

corresponding to the performance levels of immediate occupancy (IO) and life safety (LS) in the MRFs (ASCE 2007).

As observed in Fig. 11, the proposed approach has managed to efficiently limit the displacement responses by enhancing the lateral stiffness of the systems. According to 
Table 6 Variation of storey drifts and shear forces after the retrofitting $(\%)$

\begin{tabular}{|c|c|c|c|c|c|c|}
\hline \multirow{2}{*}{$\begin{array}{l}\text { Frames } \rightarrow \\
\text { Storey no }\end{array}$} & \multicolumn{2}{|l|}{ 4-Storey } & \multicolumn{2}{|l|}{ 8-Storey } & \multicolumn{2}{|c|}{ 12-Storey } \\
\hline & Drift & Shear & Drift & Shear & Drift & Shear \\
\hline 1 & -74.38 & +9.57 & -67.77 & +8.54 & -74.47 & +16.77 \\
\hline 2 & -69.15 & +4.34 & -60.57 & +9.93 & -68.64 & +16.02 \\
\hline 3 & -71.15 & -9.92 & -63.36 & +11.61 & -70.48 & +15.11 \\
\hline 4 & -85.48 & -15.23 & -63.07 & +9.45 & -69.03 & +15.53 \\
\hline 5 & * & * & -67.52 & +1.22 & -71.05 & +15.12 \\
\hline 6 & $*$ & $*$ & -66.05 & -8.80 & -70.77 & +12.45 \\
\hline 7 & $*$ & $*$ & -67.00 & -13.02 & -68.59 & +8.90 \\
\hline 8 & $*$ & $*$ & -80.73 & -33.52 & -68.55 & +6.65 \\
\hline 9 & $*$ & $*$ & $*$ & $*$ & -67.53 & +7.78 \\
\hline 10 & $*$ & $*$ & $*$ & $*$ & -71.29 & +8.71 \\
\hline 11 & $*$ & * & $*$ & * & -71.49 & +17.77 \\
\hline 12 & * & * & $*$ & * & -73.33 & +55.38 \\
\hline
\end{tabular}

Table 6, minimum percentage of reduction in storey drifts for the 4-storey frame is equal to $69.2 \%$. In contrast, rate of minimum reduction in drift values for 8 and 12-storey frames is equal to $63.1 \%$ and $67.5 \%$, respectively (see Table 6). According to Fig. 12 and Table 6, after the process of retrofitting, shear forces decreased in some of the storeys implying the significant contribution of the links to energy dissipation. Nevertheless, due to the increasing of the lateral stiffness, the base shear values were slightly increased $(9.5 \%, 8.5 \%$ and $16.7 \%$ in 4,8 and 12 -storey frames, respectively).

To evaluate the effect of the proposed retrofitting method on the local damages, Figs. 13 and 14 illustrates the distribution of the plastic hinges (flexural, shear and axial) in the members of the bare and retrofitted frames, respectively, under one of the design compatible artificial records $\left(\mathrm{R}_{5}\right.$ in Fig. 10). It can be seen that while all the three original structures exhibited damages beyond life safety (LS) level, their performance considerably improved after retrofitting intervention. The results confirm that the vertical fuse links could efficiently dissipate a large part of the earthquake input energy, and therefore, reduce the damage in the beam and column elements below the target LS level. The maximum shear strain values in the vertical links also imply that the design objective for the link elements has been fulfilled under the design earthquake intensity level $\left(\gamma_{\mathrm{y}} \leq \gamma \leq \gamma_{\mathrm{u}}\right)$.

\section{Reliability analysis of the frames individually for the storeys}

Reliability of a system indicates the probability of providing appropriate services in a specific period and under predefined conditions. Based on this definition, reliability analysis of each system entails statistical and probabilistic basics, for which the fragility curves expressing cumulative probability distribution of damages are one of the best means (Cimellaro et al. 2006). Depending on the accuracy of interest, different methods can be utilized to generate the fragility curves such as the methods based on expert judgment as well as statistical, experimental, analytical and hybrid methods (Khalvati and Hosseini 2008). 


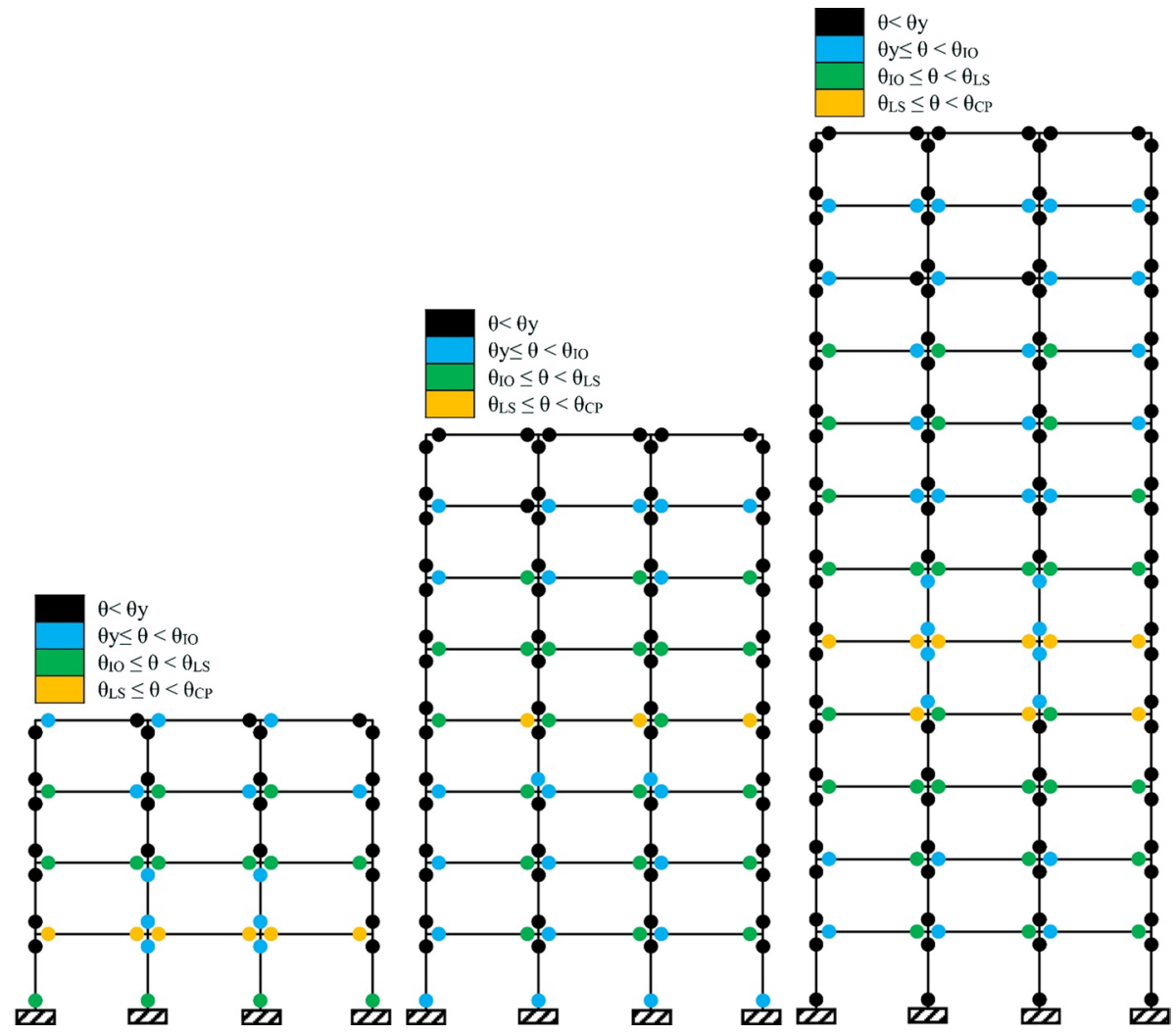

Fig. 13 Distribution of the flexural plastic hinges along the height of original frames under the DBE hazard level $\left(\mathrm{R}_{5}\right)$

The reliability analysis can be conducted respectively for a specific performance level (IM-Based) or a certain hazard level depending on the fact that the seismic intensity or the structural response parameters determine the limit state for damage (EDPBased) (Zareian et al. 2010; Mohsenian et al. 2019). In this study, the reliability analysis is conducted using the engineering demand parameter approach (EDP-Based). In this approach, it is attempted to determine the probability of reaching various performance levels (damage) under certain earthquake intensity. Given that seismic response parameters $(\mathrm{DM}=$ Damage Measure) specify the damage state, fragility curves are extracted for a certain hazard level. Despite advantages and great features of this approach, it has unfortunately received less attention that might be due to lack of knowledge towards its capabilities. It is believed that application of the EDP-based approach could be especially practical for the seismic rehabilitation/retrofitting projects, in which it is attempted to satisfy a specific performance level under a certain earthquake hazard level. In this approach, the following procedure is followed:

First, a suite of accelerograms compatible with the site conditions is selected and then, they are scaled to a certain hazard level (IM = Constant). Subsequently, using these accelerograms, the structure is analyzed to capture the required responses (DM). In the next step, assuming a lognormal distribution for the response values, after calculating 

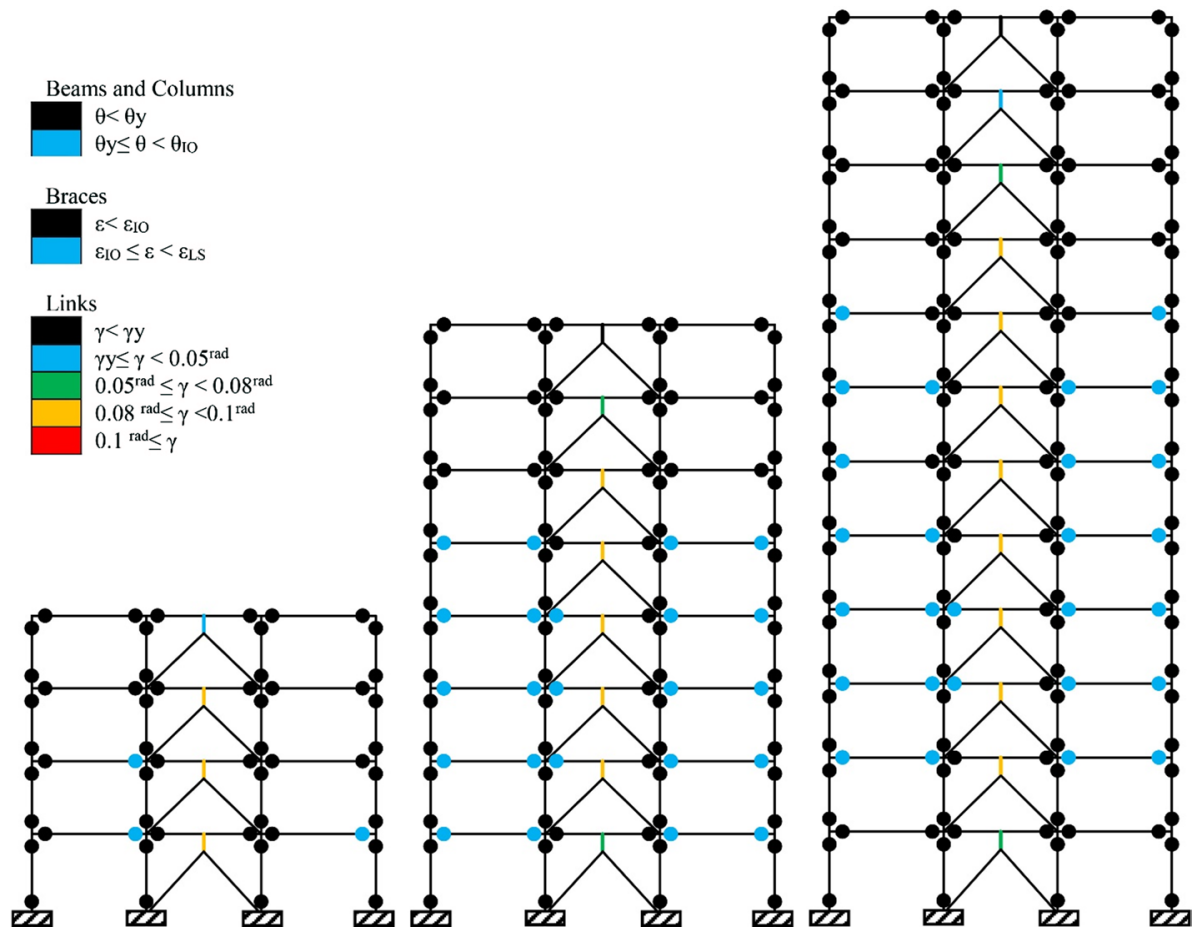

Fig. 14 Distribution of the Flexural, Shear and Axial Plastic Hinges in Height of the rehabilitated Frames under the DBE Hazard Level $\left(\mathrm{R}_{5}\right)$

the mean $(\mu)$ and variance $(\sigma)$ parameters for the values obtained for this level of intensity, a probability density function $(\mathrm{f}(\mathrm{x})$ ) is extracted as in Eq. (16) (Nowak and Collins 2012):

$$
\mathrm{f}(\mathrm{x})=\frac{1}{\sigma \sqrt{2 \pi}} \operatorname{EXP}\left(\frac{(x-\mu)^{2}}{-2 \sigma^{2}}\right)
$$

As schematically shown in Fig. $15 \mathrm{a}$, by replacing a value for $\mathrm{X}_{0}$ as the response corresponding to a specific performance level, the area under the density function from $-\infty$ to $\mathrm{X}_{0}$ denotes the reliability, which means that at this level of intensity, to probability of $\mathrm{P}$, the response parameter will not reach the limit values corresponding to this damage level (Mohsenian et al. 2019; Mohsenian and Mortezaei 2018a). Finally, $\mathrm{P}_{0}$ represents the fragility probability that specifies the likeliness of experiencing the specified damage level at this level of intensity $\left(\mathrm{P}_{0}=1-\mathrm{P}\right)$. A reliability curve can be then derived for each intensity level by considering continues range for the variable $\mathrm{X}_{0}$ as the response and computing probability values, $\mathrm{P}$, according to the described approach (Fig. 15b).

In the present study, the artificial records produced in the previous section are used to conduct reliability analysis (see Fig. 10). Storey drift and shear strain in the link beam elements were taken as the response parameters (DM) to perform the reliability analysis for both cases of the original and retrofitted frames.

It should be noted that majority of the previous studies have employed the maximum response of the entire structure as the response parameter, regardless of its location in 
(a)

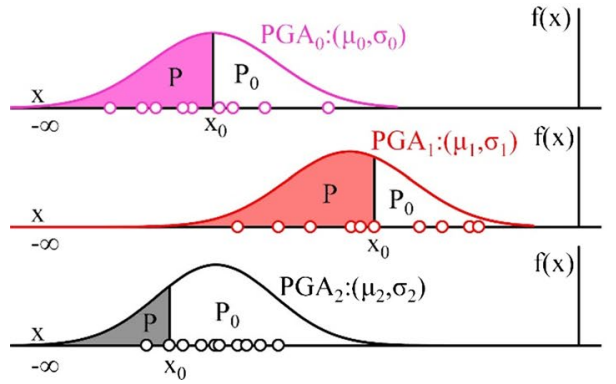

(b)

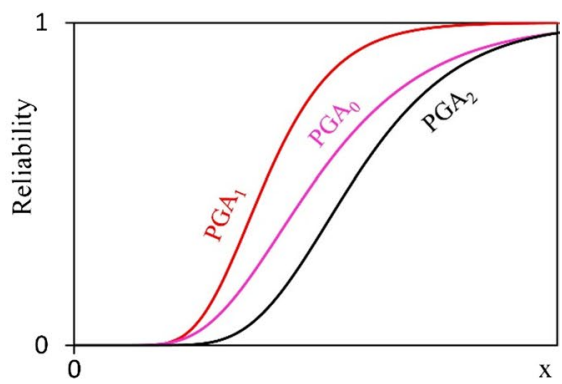

Fig. 15 Reliability analysis using the EDP-based approach a: Probability density functions for each intensity level; b: Probability cumulative distribution functions for each hazard level

plan or elevation. With respect to the point that different accelerograms lead to various damage states, and given that each of them could cause greater excitation in particular locations of the structure, choosing the appropriate response parameter is counted as one of the main challenges for reliability analysis. To tackle on this challenge, the best solution is to capture the responses in a storey-by-storey manner, by which the reliability of the load-carrying system of each storey can be analyzed individually. Accordingly, this scenario is adopted in this study, and for each storey the maximum values of drift and shear strain in the links were captured as the main response parameters. Subsequently, based on the procedure explained earlier and in proportion to the limit states of interest, the reliability of structures before and after rehabilitation was derived individually for each storey as shown in Figs. 16, 17, 18.

Based on the results, it can be concluded that the rehabilitation objective has been fulfilled for all the designed frames. According to Fig. 16, when the drift corresponding to the LS performance level is of concern $\left(\delta_{\mathrm{LS}}=2.5 \%\right)$, the rate of improvement in reliability of the most critical storey is between 64 to $68 \%$. In the case of drifts corresponding to performance levels of $\mathrm{CP}\left(\delta_{\mathrm{CP}}=5.0 \%\right)$, reliability was not considerably varied before and after the retrofitting intervention. However, the reliability of $100 \%$ was captured for all storeys under the DBE hazard level. Importantly, the results indicate that combination of the MRFs and eccentric bracing system equipped with vertical link can provide both multilevel energy absorption capability and lateral load-resisting capacity to resist either higher levels of earthquake intensity or probable aftershocks.

As observed in Fig. 17, the vertical links in almost all storeys yield under DBE. Additionally, at this level of intensity, reliability of not reaching the strain of $0.1^{\mathrm{rad}}$ in the links of the 4, 8 and 12-storey frames is estimated at least 94, 92 and 93\%, respectively. On this basis, it is concluded that the primary purpose of the design of the vertical links has been properly satisfied. This is in complete agreement with the results presented in the previous section.

Figure 18 demonstrates that the maximum strain in the braces has been constantly lower than the compressive strain corresponding to the performance level of IO $\left(\varepsilon_{\mathrm{IO}}\right)$. Consequently, it is concluded that these members remained elastic and did not contribute to the energy dissipation of the system. 
Original frame

Retrofitted frame
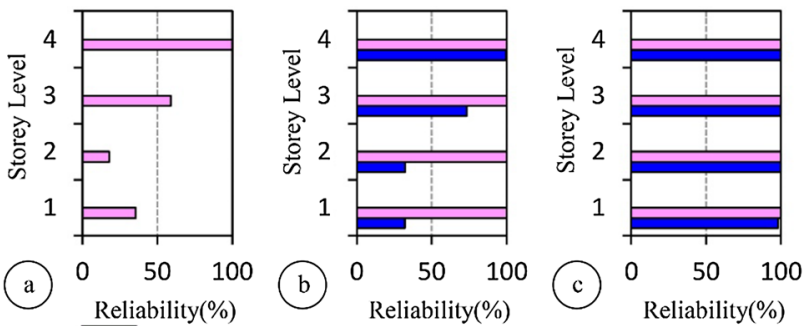

Original frame

Retrofitted frame
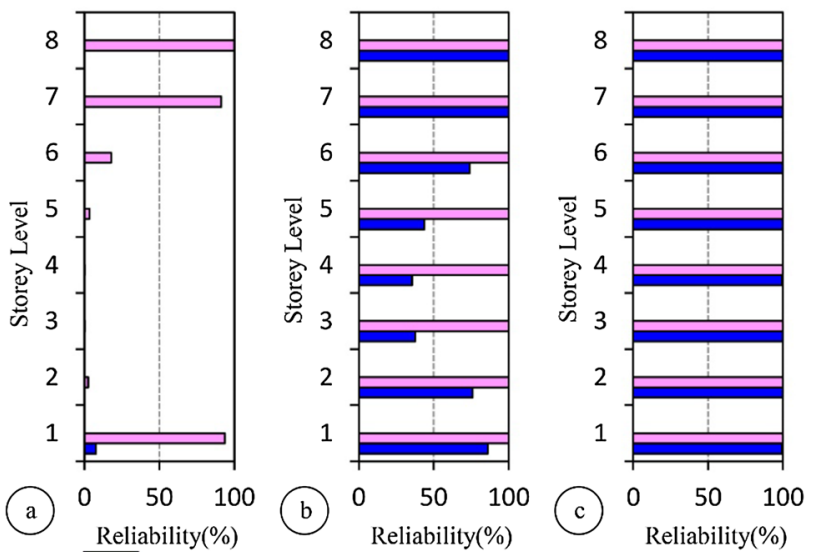

Original frame

Retrofitted frame
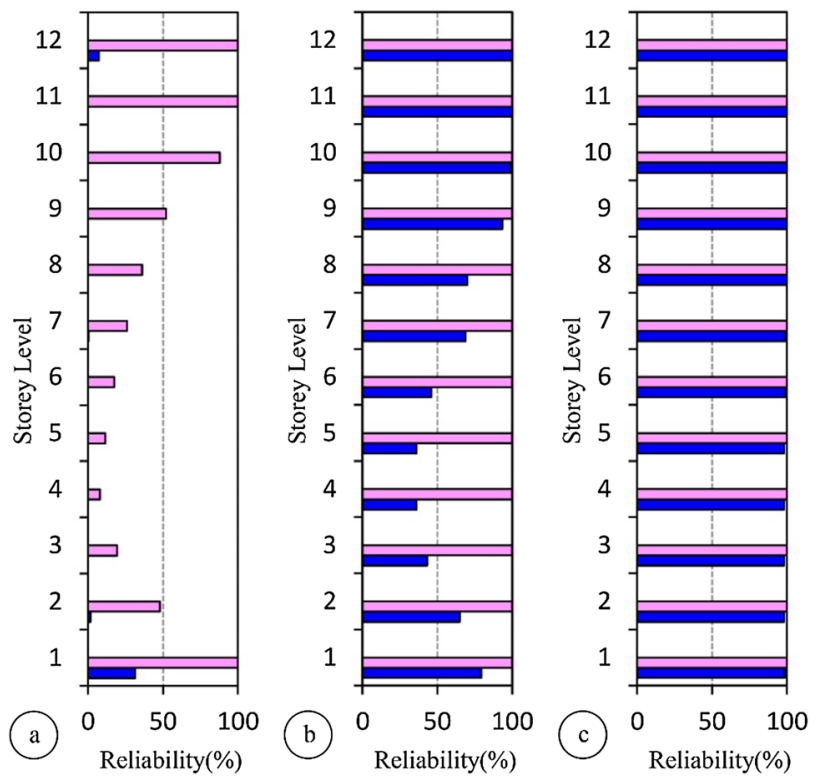

Fig. 16 Reliability of MRFs for not exceeding the performance levels of a IO, b LS, c CP 


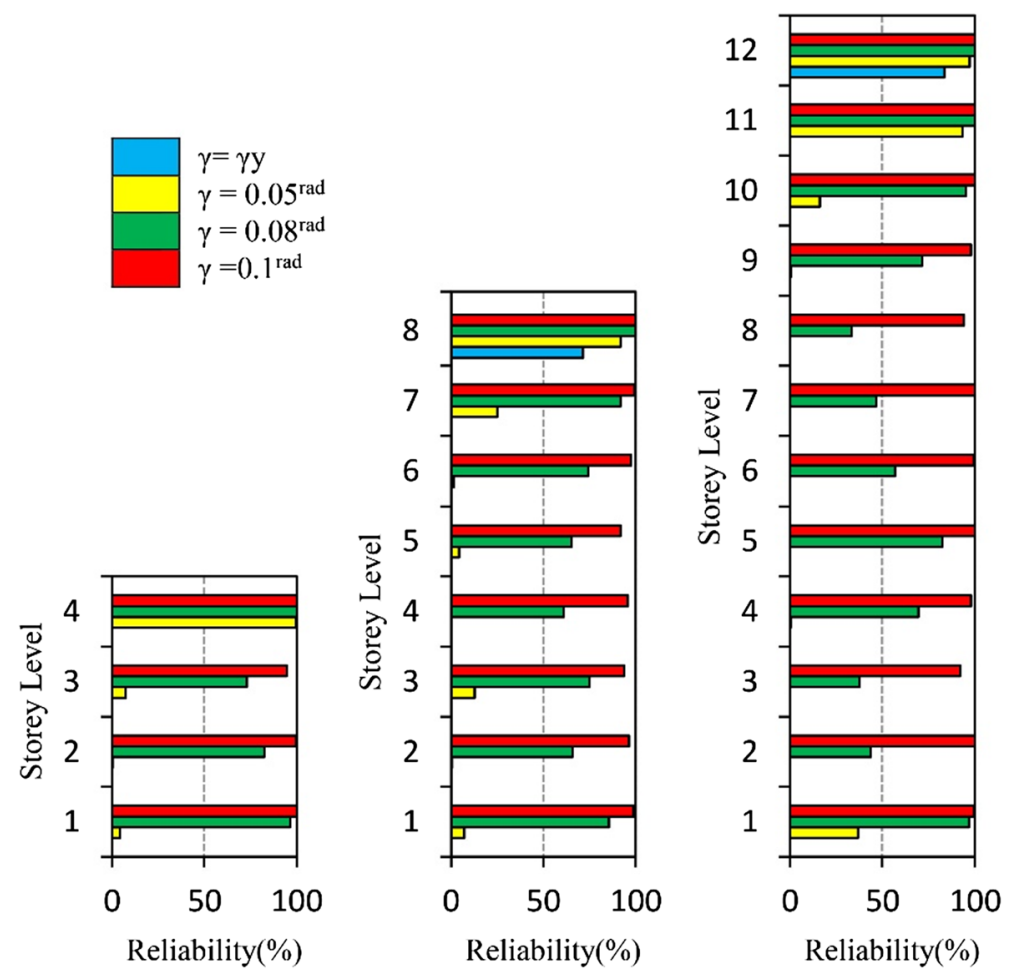

Fig. 17 Reliability of not exceeding different damage levels in vertical links

\section{Global reliability analysis of the frames}

In the case of systems comprised of several subsystems that possess a unique response and particular damage states in proportion to their functionality, reliability curves are usually presented for each subsystem individually. Depending on the succession of damages in the subsystems, their interaction and expected damage levels, it would be more reasonable to perform the reliability analysis of the whole system for a combination of different damage states in the subsystems, which are not typically observed. For instance, as schematically depicted in Fig. 19, considering the combined system of MRF and eccentric bracing with vertical link, the members of these two systems can provide energy dissipation and lateral load-carrying capacity. Accordingly, each storey can be divided into two separate subsystems.

In the case of MRF, the damage states (or performance levels) can be defined using various limits for the storey drift ( $\delta$ ). Likewise, damage states can be determined for the eccentric bracing system by defining the limits for shear strain of the links $(\gamma)$ and axial strain of the braces ( $\varepsilon$ ) (see Figs. 8 and 9). According to Fig. 19, although the reliability of each group of members in the ith storey under a certain level of intensity $\left(\mathrm{PGA}_{0}\right)$ is known (Eqs. (17-19)), the conventional methods are unable to respond if the reliability for a combination of damage states for a single storey (or the whole frame) is of concern (see Eq. (20)). This is one of the other shortcomings associated with the reliability analysis studies and development of the fragility curves. In this respect, the designers will always 

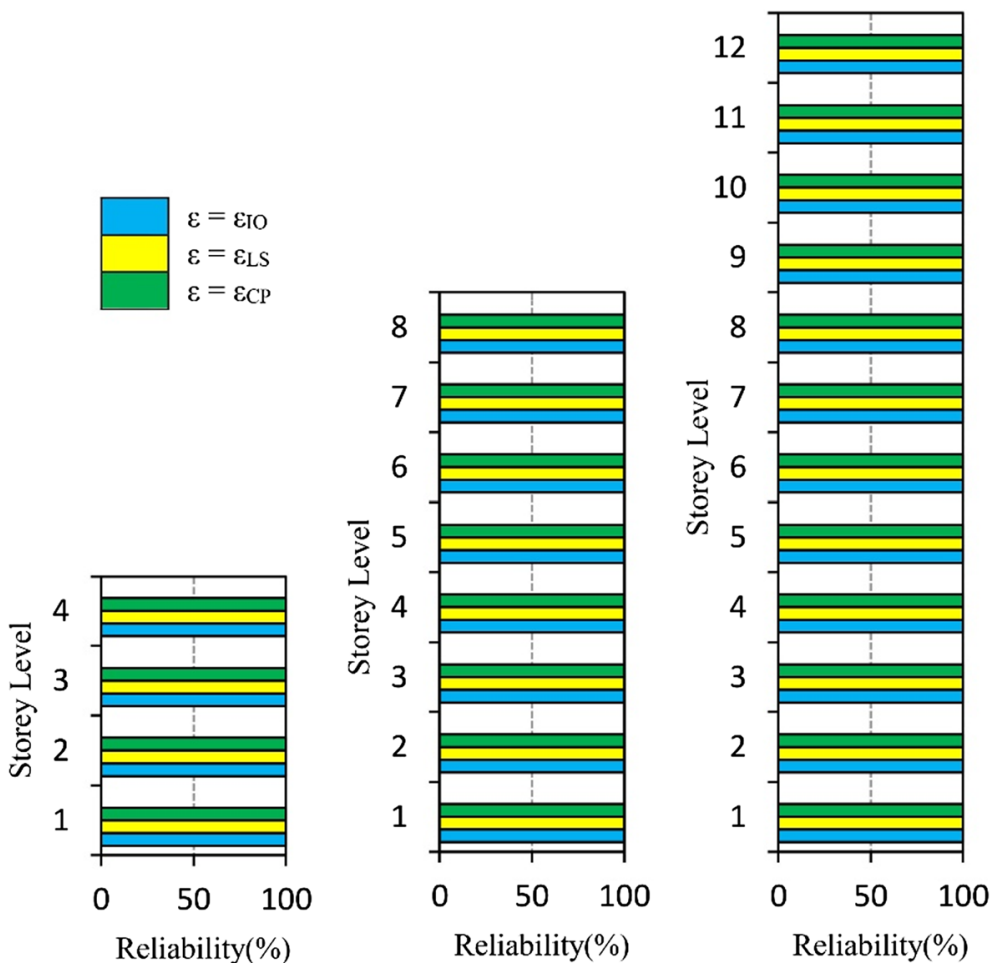

Fig. 18 Reliability of not exceeding different damage levels in diagonal members

face the question that "how much each storey contributes to the global reliability of the structure and how various damage states of the subsystems can be correlated?". The best approach to appropriately answer this question is to simulate the frame by the systems comprised of components with serial, parallel and combined functionality, as applied in this study (Frangopol et al. 2007; Nielson and DesRoches 2007; Mortezaei and Mohsenain 2019). This indicates that different performance levels should be considered in the reliability analyses as follows:

$$
\begin{gathered}
\mathrm{R}\left[\delta \leq \mathrm{x}_{0} \mid \mathrm{PGA}=\mathrm{PGA}_{0}\right]_{\mathrm{i}}=\mathrm{P}_{0} \\
\mathrm{R}\left[\gamma \leq \mathrm{x}_{1} \mid \mathrm{PGA}=\mathrm{PGA}_{0}\right]_{\mathrm{i}}=\mathrm{P}_{1} \\
\mathrm{R}\left[\varepsilon \leq \mathrm{x}_{2} \mid \mathrm{GA}=\mathrm{PGA}_{0}\right]_{\mathrm{i}}=\mathrm{P}_{2} \\
\mathrm{R}\left[\delta \leq \mathrm{x}_{0}, \gamma \leq \mathrm{x}_{1}, \varepsilon \leq \mathrm{x}_{2} \mid \mathrm{PGA}=\mathrm{PGA}_{0}\right]_{\text {storey or Frame }}=?
\end{gathered}
$$

\subsection{Series configuration}

As shown in Fig. 20, an n-component series system is able to provide services as far as each component safely serves in the circuit. In series systems, given that outage of each 


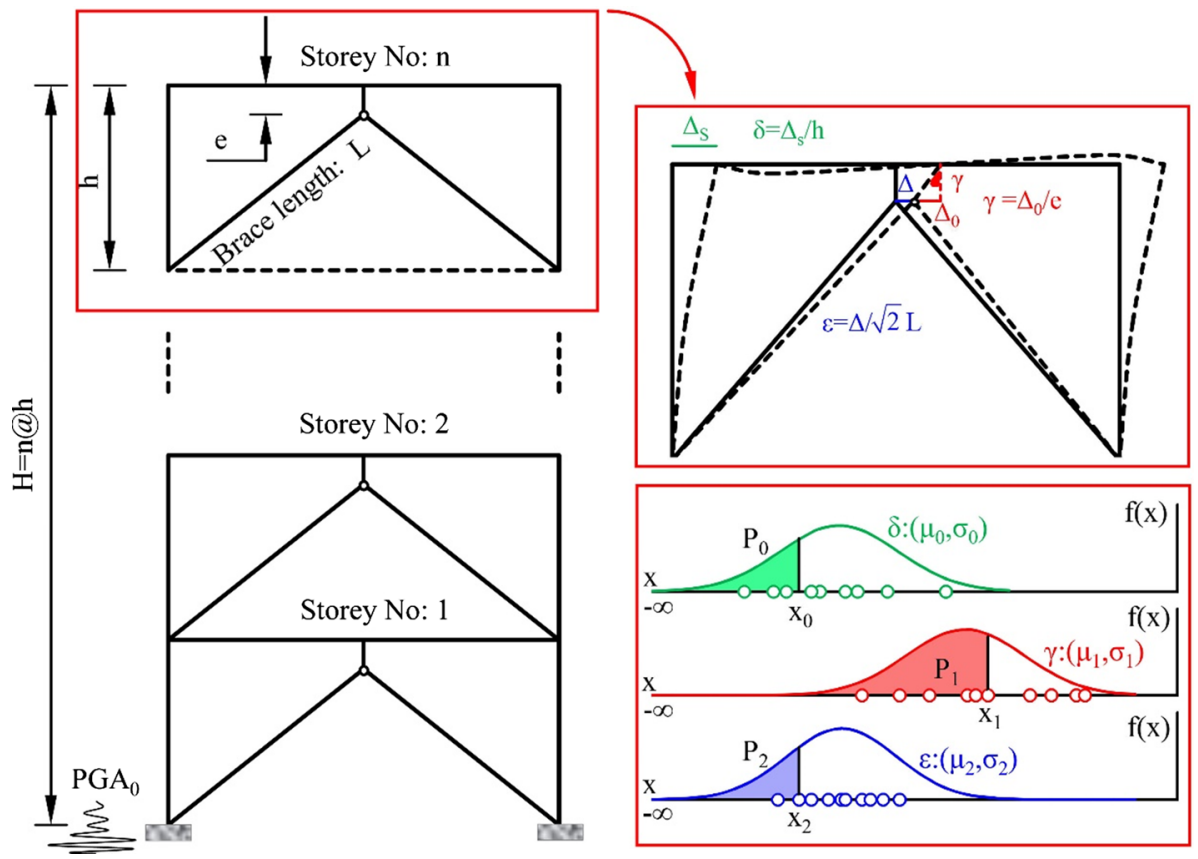

Fig. 19 Schematic representation of calculating the reliability of different groups of members for a hypothetical performance level $\left(\mathrm{x}_{0}, \mathrm{x}_{1}, \mathrm{x}_{2}\right)$ under a certain hazard level $\left(\mathrm{PGA}_{0}\right)$

Fig. 20 Configuration of a series system composed of "n" components
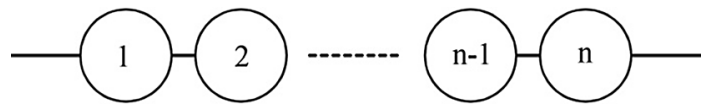

component results in interruption of whole system, every single component is deemed critical. In this respect, assuming dependency for the components and considering $\mathrm{R}_{\mathrm{i}}$ as the reliability of the ith member, reliability of whole system $\left(\mathrm{R}_{\text {System }}\right)$ is derived by Eq. (21). Obviously, global reliability of the system will not be greater than the lowest reliability of the components.

$$
\mathrm{R}_{\text {System }}=\mathrm{R}_{1} \cdot \mathrm{R}_{2} \ldots \mathrm{R}_{(\mathrm{n}-1)} \cdot \mathrm{R}_{\mathrm{n}}=\prod_{i=1}^{n}[R i] \leq \min \{\mathrm{Ri}\}
$$

\subsection{Parallel configuration}

Figure 21 demonstrates that an n-component parallel system provides services as far as at least one member serves in the circuit. In other words, the system will be interrupted when all components fail. Similarly, assuming dependent components and taking $\mathrm{R}_{\mathrm{i}}$ as reliability of the ith member, reliability of whole system $\left(R_{\text {System }}\right)$ is obtained from Eq. (22). Clearly, as the number of components increases, reliability of the system will rise subsequently. On 
Fig. 21 Configuration of a parallel system composed of $n$ components

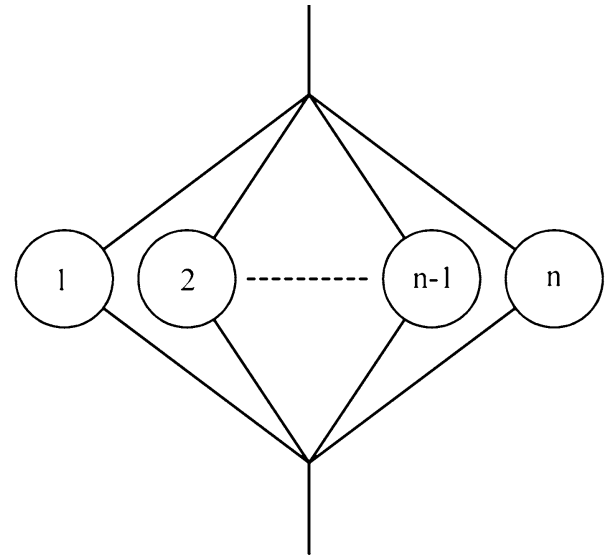

the other hand, global reliability of the system will be greater than the highest reliability of the components.

$$
\mathrm{R}_{\text {System }}=1-\left(1-\mathrm{R}_{1}\right) \cdot\left(1-\mathrm{R}_{2}\right) \ldots\left(1-\mathrm{R}_{(\mathrm{n}-1)}\right) \cdot\left(1-\mathrm{R}_{\mathrm{n}}\right)=1-\prod_{i=1}^{n}[1-\mathrm{Ri}] \geq \max \{\mathrm{Ri}\}
$$

\subsection{Combined series-parallel configuration}

In reality, there are very rare cases of structures to be exclusively classified as the series or parallel systems. Majority of the structural systems are present in form of the combination of series and parallel systems, which are technically known as combined systems. To calculate reliability of such systems, the system network is broken to several subsystems whose reliability will be computed and then, global reliability will be determined by combining the reliability of each subsystem. For the configuration shown in Fig. 22, reliability of the system ( $\mathrm{R}_{\text {System }}$ ) is derived based on Eq. (23) by considering "m" lines, "n" components in each line, and $\mathrm{Ri}$ as the reliability of $\mathrm{i}^{\text {th }}$ component. It should be mentioned that in the Eq. (23), "j" denotes the number of lines.

Fig. 22 Configuration of a combined series-parallel system

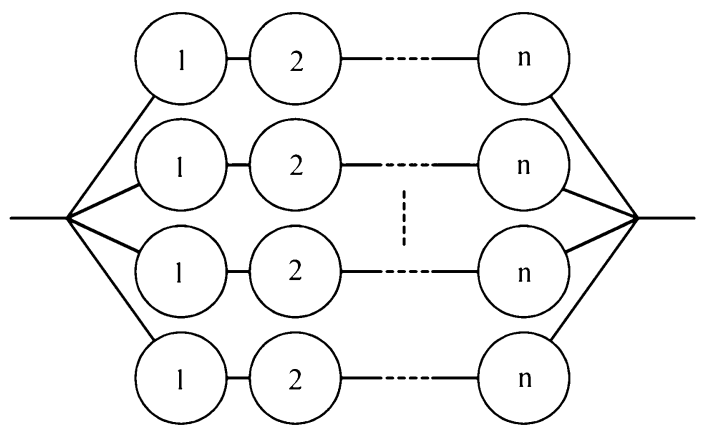




$$
\mathrm{R}_{\text {System }}=1-\prod_{j=1}^{m}\left[1-\prod_{i=1}^{n} \mathrm{Ri}\right]
$$

\subsection{Configuration adopted for the studied Models}

Assuming that failure of only one storey leads to failure of whole frame, according to the configuration demonstrated in Fig. 23, each n-storey frame can be deemed as an n-component series system in which reliability of each component is provided by the MRF and the eccentric bracing system. In each storey of the rehabilitated frame, the vertical link is only able to absorb energy if the braces do not buckle and carry loads continuously (see Fig. 19). Consequently, it can be concluded that in each storey, the link and braces act as a series system. However, in the case of vertical link's failure (e.g. due to the buckling of the braces or fracture of the links), presence of the MRF assists the storey in maintaining its load-resisting capacity. Thereby, in each storey, the MRFs and eccentric bracing system act parallel. The reliability of the combined configuration depicted in Fig. 23 is obtained based on Eq. (24).

$$
\mathrm{R}_{\text {System }}=1-\prod_{i=1}^{n}[(1-\mathrm{R}(\mathrm{B}) \mathrm{i} . \mathrm{R}(\mathrm{L}) \mathrm{i}) .(1-\mathrm{R}(\mathrm{MF}) \mathrm{i}]
$$

A summary of the steps for evaluating the reliability of the frame structures with the configuration shown in Fig. 23 is as follows (Mohsenian et al. 2020a, b, c):

(1) According to the description given at the beginning of Sect. 6, under the design basis hazard level, the reliability curves are extracted separately for the different groups of structural members in the storeys (vertical links (L), Braces (B) and the combination of beams and columns as moment resisting frames (MF)).

(2) In each storey, the reliability curves for the groups of structural members are combined according to the explanations given for the configuration presented in Fig. 23. Consequently, each storey has a reliability curve for each damage state in the group of structural members (see Fig. 24).

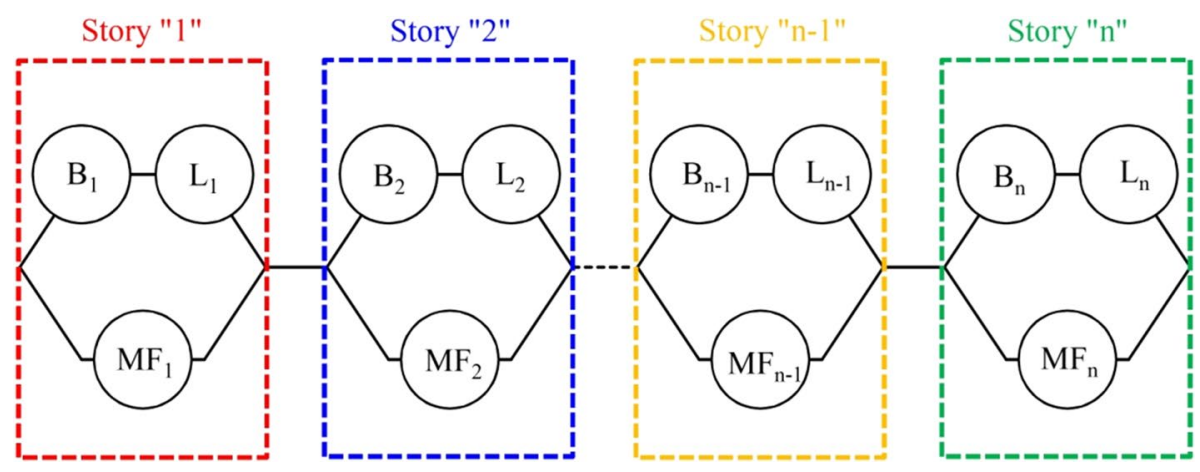

Fig. 23 Configuration adopted for the n-storey rehabilitated frame 


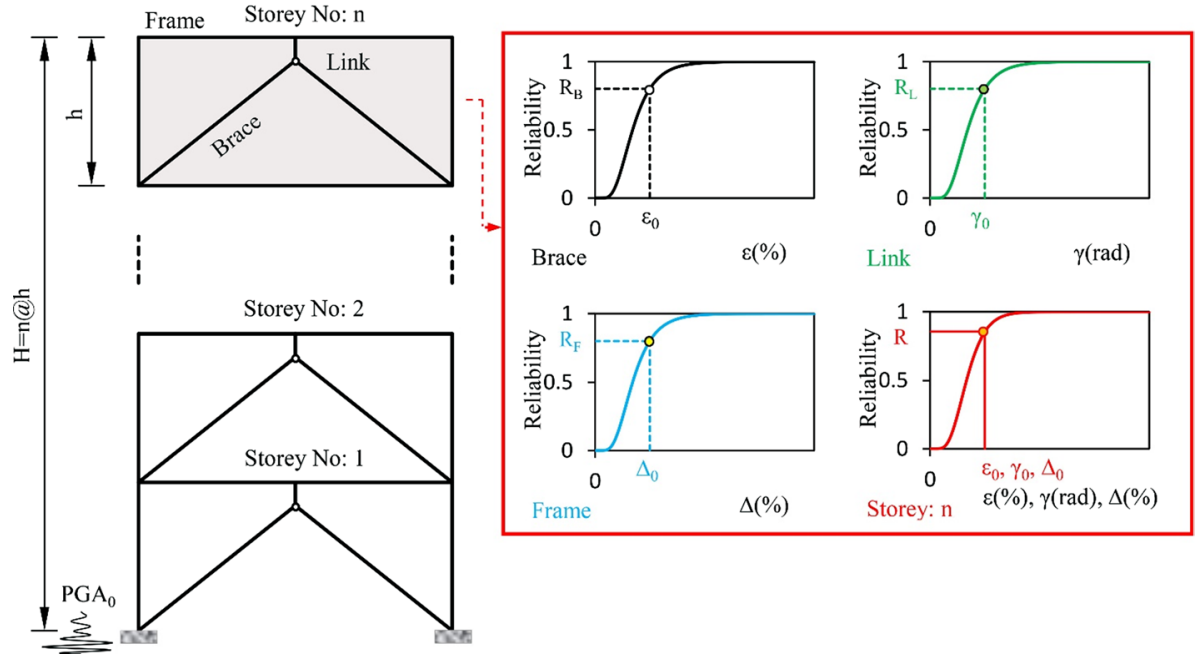

Fig. 24 Process of extracting reliability curves for each storey (schematic)

(3) According to Fig. 25, considering the series performance of the storeys, the reliability curves of storeys are combined based on the explanations and relationships presented in Sect. (7.1). At the end of this step, considering the combination of the desired damage states in the groups of structural members, a single reliability curve will be extracted for the whole structure.
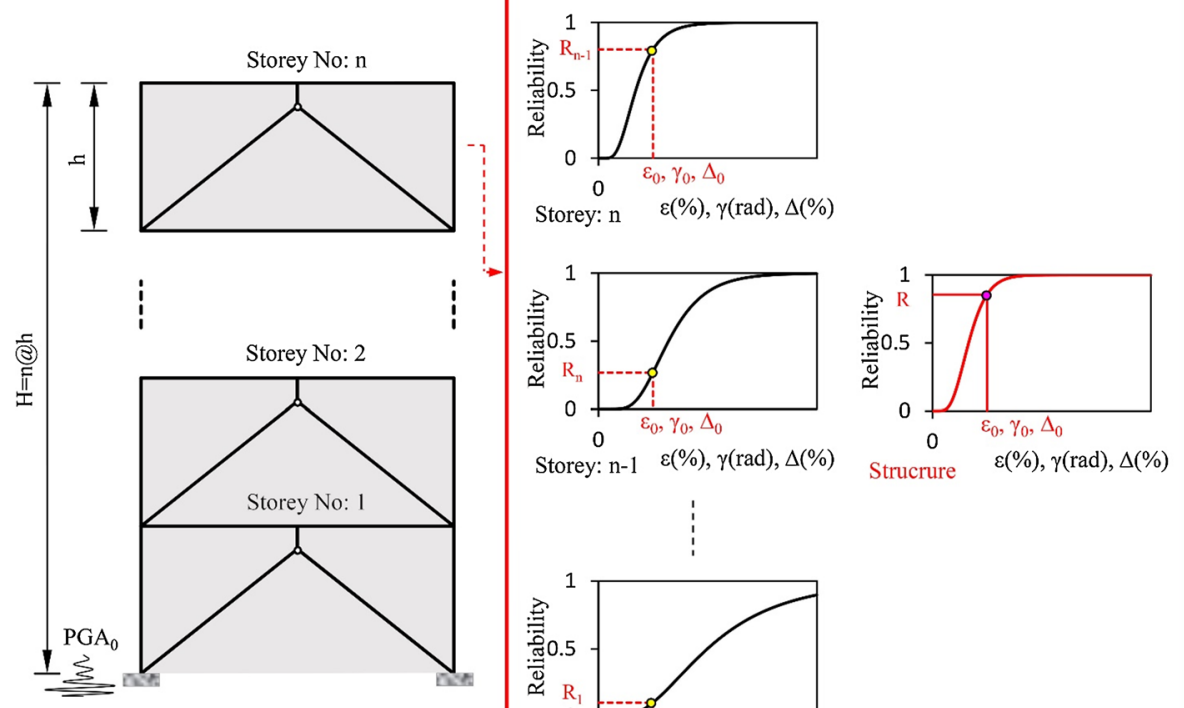

Storey: n-1 $\varepsilon(\%), \gamma(\mathrm{rad}), \Delta(\%)$

Strucrure $\varepsilon(\%), \gamma(\mathrm{rad}), \Delta(\%)$

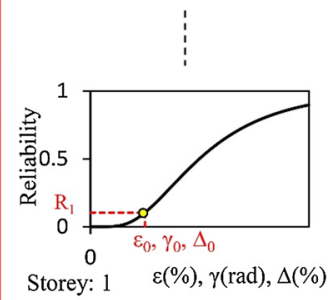

Fig. 25 Process of extracting reliability curves for the structure (schematic) 
It should be noted that, due to large number of reliability curves of the storeys obtained in this study (108 curves in total), they are not provided in the manuscript. However, the schematic process for extracting the reliability curves is demonstrated in Figs. 24 and 25.

According to the provided description, the reliability of each retrofitted model for the various combinations of the damage and performance levels in the lateral load carrying systems of the frames is plotted and presented in Fig. 26. Based on the maximum storey drifts, performance levels of IO $\left(\delta_{\mathrm{IO}}=0.7 \%\right)$, LS $\left(\delta_{\mathrm{LS}}=2.5 \%\right)$ and $\mathrm{CP}\left(\delta_{\mathrm{CP}}=5.0 \%\right)$ have been considered for the MRFs. It is worth noting that design process has been conducted in such a way that the links act as the seismic fuse and braces provide highest performance level. Thus, considering a constant performance level for the MRF and the brace elements,
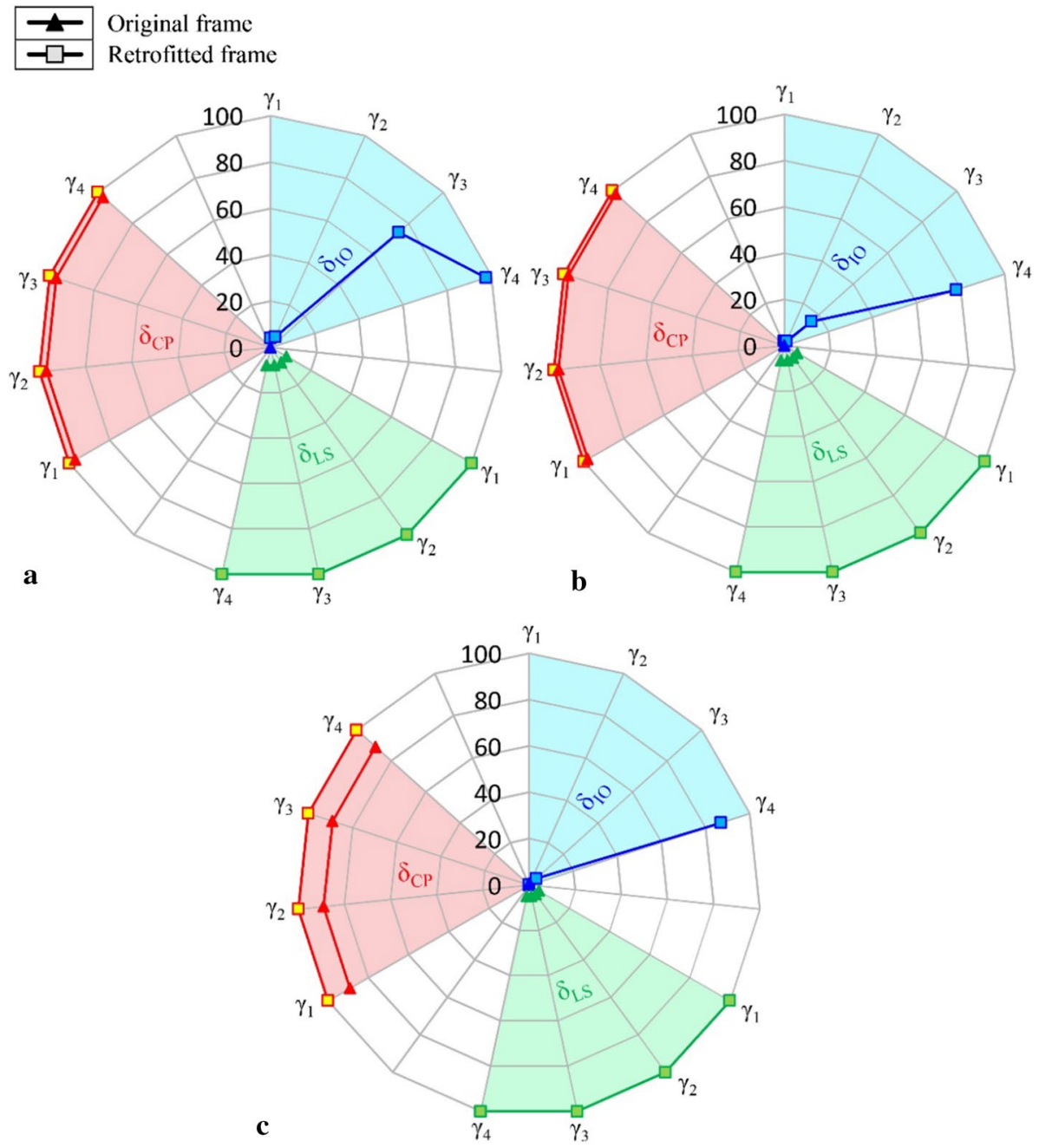

Fig. 26 Reliability for different damage levels in lateral load-resisting systems a 4-storey frame, b 8-storey frame, and c 12-storey frame 
only the damage level corresponding to the sear links ( $\gamma 1-4$ in Fig. 8) are considered as variable (see Fig. 8).

As observed, the proposed retrofitting method has significantly affected the seismic performance of the frames under the DBE hazard level for drift values corresponding to the performance level of LS in the MRFs $\left(\delta_{\mathrm{LS}}\right)$. For this drift limit, the reliability of the 4, 8 and 12 -storey frames has respectively improved by $92 \%, 93.5 \%$ and $95 \%$ for various levels of damage in the links.

At the same level of intensity, in the case when the drift corresponding to the performance level of $\mathrm{CP}\left(\delta_{\mathrm{CP}}\right)$ for the MRFs is of concern, the reliability increased by $3 \%, 2 \%$ and $11 \%$ for the 4,8 and 12 -storey frames, respectively.

Based on the results, at this intensity level and for the drift corresponding to the performance level of $\mathrm{CP}\left(\delta_{\mathrm{CP}}\right)$, reliability of the frame before and after retrofitting is $90 \%$ and $100 \%$, respectively. Obviously, greater levels of intensity are required so that higher damage levels could occur. It can be noted that the response of the shorter frames and those with higher levels of performance were more affected by using the vertical links. This is attributed to the fact that as by decreasing the height, the elastic stiffness of the system increases and thus the role of the vertical links becomes more profound.

It should be mentioned that the uncertainties due to assembling errors and material properties can affect the response of the structures. However, previous studies showed that the seismic ground motion is the main source of uncertainty in the seismic design of structures (Hajirasouliha et al. 2016). The above observations are also limited to the frames and assumptions made in this study. However, the main conclusions are general and the results of this study should prove useful in more efficient design and performance assessment of multi-storey steel moment resisting frames with vertical shear links.

\section{Summary and conclusions}

This study presented the detailed design process of the bracing system equipped with vertical links and investigated the impact of this system on the seismic performance of the existing steel moment-resisting frames (MRFs). Based on the results obtained from a comprehensive reliability assessment analysis on 4, 8 and 12-storey frames, it was concluded that the proposed system can efficiently improve the seismic performance of the weak MRFs under the target hazard level. A novel combined series-parallel system approach was adopted to conduct the reliability analysis. The major advantage of this approach is that not only the contribution of each storey to the structure's reliability can be specified, but also the reliability of the structure for a combination of various damage states of the lateral load-carrying members can be captured. The most important findings of this study are as follows:

- The results of the analysis show that the proposed retrofitting method could considerably increase the lateral stiffness of the systems, and consequently reduce the period of the first vibration modes (by at least $49 \%$ ).

- It was found that under the target earthquake, in the cases when the drift corresponding to the performance level of life safety (LS) is of concern for the frames $\left(\delta_{\mathrm{LS}}=2.5 \%\right)$, the reliability of all the designed frames were greater than $64 \%$ for the most critical storey of each retrofitted system. However, it was observed that under the same earthquake event, the reliability of the retrofitted frames did not improve 
significantly for the case of drift corresponding to the collapse prevention $(\mathrm{CP})$ performance level $\left(\delta_{\mathrm{CP}}=5.0 \%\right)$, mainly due to the good seismic performance of the original frames for this performance level. These findings indicate that the combination of moment-resisting frames and the eccentric bracing system with vertical link can provide both multi-level energy absorption capability and sufficient lateral loadresisting capacity to experience the intensity levels higher than that of the target earthquake.

- It was observed that in most storey levels, the vertical links yield when subject to the target earthquake. At this level of intensity, the reliability of the links for not reaching the strain of $0.1^{\mathrm{rad}}$ (the strain corresponding to occurrence of the ultimate stress in the link) was estimated to be at least $92 \%$.

- It was found that the strain in the braces is constantly lower than the compressive strain corresponding to the performance level of immediate occupancy $\left(\varepsilon_{\mathrm{IO}}\right)$. As a result, it can be stated that these members remain elastic and make no contribution to energy dissipation of the system.

- By considering the drift corresponding to the performance level of life safety $\left(\delta_{\mathrm{LS}}\right)$ as the target, it was shown that the proposed retrofitting method greatly improved the global reliability of the systems (by at least $92 \%$ ) for various levels of damage to the vertical links. At the same level of intensity and for drifts corresponding to the performance level of $\mathrm{CP}\left(\delta_{\mathrm{CP}}\right)$, the reliability of the studied systems after retrofitting was close to $100 \%$ for all damage states induced to the links. This highlights the potential of the eccentric bracing system in providing a multi-level combined system to resist the induced lateral loads.

Author contributions Conceptualization: VM; Methodology: VM; Formal analysis and investigation: VM; Writing-original draft preparation: RF, VM; Writing-review and editing: IH; Validation IH; Supervision: IH.

Funding Not applicable.

\section{Compliance with ethical standards}

Conflict of interest The authors have no relevant financial or non-financial interests to disclose.

Availability of data and material Upon reasonable request from the authors.

Informed consent All authors whose names appear on the submission: Made substantial contributions to the conception or design of the work; or the acquisition, analysis, or interpretation of data; or the creation of new software used in the work; Drafted the work or revised it critically for important intellectual content; Approved the version to be published; and Agree to be accountable for all aspects of the work in ensuring that questions related to the accuracy or integrity of any part of the work are appropriately investigated and resolved.

Open Access This article is licensed under a Creative Commons Attribution 4.0 International License, which permits use, sharing, adaptation, distribution and reproduction in any medium or format, as long as you give appropriate credit to the original author(s) and the source, provide a link to the Creative Commons licence, and indicate if changes were made. The images or other third party material in this article are included in the article's Creative Commons licence, unless indicated otherwise in a credit line to the material. If material is not included in the article's Creative Commons licence and your intended use is not 
permitted by statutory regulation or exceeds the permitted use, you will need to obtain permission directly from the copyright holder. To view a copy of this licence, visit http://creativecommons.org/licenses/by/4.0/.

\section{References}

ABAQUS (2014) Version 6.14, ABAQUS Users Manual, SIMULIA World Headquarters. Rissing Sun Mills 166 Valley Street, Providence (RI 02909-2499, USA)

AISC (2010) Specification for structural steel buildings, ANSI/AISC 360-10. American Institute of Steel Construction Inc, Chicago, IL

ASCE (2007) Seismic rehabilitation of existing buildings, ASCE/SEI41-06. American Society of Civil Engineers, Reston

ASCE (2010) Minimum design loads and associated criteria for buildings and other structures, ASCE/SEI 7-10. American Society of Civil Engineers, Reston, Virginia

ASCE (2017) Seismic rehabilitation of existing buildings, ASCE/SEI41-17. American Society of Civil Engineers, Reston, Virginia

ASTM A36/A36M-19 (2019) Standard specification for carbon structural steel, ASTM International, West Conshohocken

Baradaran MR, Hamzezarghani F, RastegariGhiri M, Mirsanjari Z (2015) The effect of vertical shear-link in improving the seismic performance of structures with eccentrically bracing systems. Int J Civil Environ Eng 9(8):1078-1082

Bouwkamp J, Vetr MG, Ghamari A (2016) An analytical model for inelastic cyclic response of eccentrically braced frame with vertical shear link (V-EBF). Case Stud StructEng 6:31-44

Bozkurt MB, Topkaya C (2018) Replaceable links with gusseted brace joints for eccentrically braced frames. Soil DynEarthqEng 115:305-318

Chesoan A, Stratan A, Dubina D (2018) Design implementation of re-centring dual eccentrically braced frames with removable links. Soil DynEarthqEng 112:174-184

Cimellaro GP, Reinhorn AM, Bruneau M, Rutenberg A (2006) Multi-dimensional fragility of structures: formulation and evaluation, Technical report MCEER-06-0002

Computers and Structures Inc. (CSI) (2017) Structural and earthquake engineering software, PERFORM3D nonlinear analysis and performance assessment for 3D structures, Version 7.0.0, Berkeley, CA, USA

Computers and Structures Inc. (CSI) (2015), Structural and earthquake engineering software, ETABS, extended three dimensional analysis of building systems nonlinear, Version 15.2.2, Berkeley, CA, USA

Daryan A, Bahrampoor H, Ziaei M, Golafshar A, Assareh MA (2008) Seismic behavior of vertical shear links made of easy-going steel. Am J EngApplSci 1(4):368-377

Della Corte G, D'Aniello M, Landolfo R (2013) Analytical and numerical study of plastic overstrength of shear links. J Constr Steel Res 82:19-32

Di Sarno L, Elnashai AS (2009) Bracing systems for seismic retrofitting of steel frames. J Constr Steel Res 65(2):452-465

Duan L, Su M (2017) Seismic testing of high-strength steel eccentrically braced frames with a vertical link. ProcInst Civil Eng-Struct Build 170(11):874-882

Engelhardt MD, Popov EP (1992) Experimental performance of long links in eccentrically braced frames. J StructEng (ASCE) 118(11):3067-3088

Frangopol D, Kawatani M, Kim WC (2007) Reliability and optimization of structural systems: assessment, design, and lift-cycle performance, 1st edn. CRC Press, Boca Raton

Hajirasouliha I, Pilakoutas K, Mohammadi RK (2016) Effects of uncertainties on seismic behaviour of optimum designed braced steel frames. Steel Compos Struct 20(2):317-335

Hancock J, Watson-Lamprey J, Abrahamson NA, Bommer JJ, Markatis A, McCoy E, Mendis R (2006) An improved method of matching response spectra of recorded earthquake ground motion using wavelets. J EarthqEng 10:67-89

ISCP Permanent Committee for Revising the Standard 2800 (2014) Iranian code of practice for seismic resistant design of buildings, 4th edn. Building and Housing Research Center, Tehran

Ji X, Wang Y, Ma Q, Okazaki T (2015) Cyclic behavior of very short steel shear links. J StructEng (ASCE) 142(2):04015114

Kasai K, Popov EP (1986) General behavior of WF steel shear link beams. J StructEng 112(2):362-382

Khalvati AH, Hosseini M (2008) A new methodology to evaluate the seismic risk of electrical power substations. The 14th word conference on earthquake engineering, Beijing, China 
Lian M, Su M (2017) Seismic performance of high-strength steel fabricated eccentrically braced frame with vertical shear link. J Constr Steel Res 137:262-285

Mansour N, Christopoulos C, Tremblay R (2011) Experimental validation of replaceable shear links for eccentrically braced steel frames. J StructEng (ASCE) 137(10):1141-1152

Mazzolani F, Della Corte G, D'Aniello M (2009) Experimental analysis of steel dissipative bracing systems for seismic upgrading. J Civil EngManag 15(1):7-19

Mohsenian V, Filizadeh R, Ozdemir Z, Hajirasouliha I (2020) Seismic performance evaluation of deficient steel moment-resisting frames retrofitted by vertical link elements. Structures 26:724-736

Mohsenian V, Filizadeh R, Hajirasouliha I, Garcia R (2021) Seismic performance assessment of eccentrically braced steel frames with energy-absorbing links under sequential earthquakes. J Build Eng 33:101576-101576

Mohsenian V, Gharaei-Moghaddam N, Hajirasouliha I (2020) Reliability analysis and multi-level response modification factors for buckling restrained braced frames. J Constr Steel Res 171:106137

Mohsenian V, Hajirasouliha I, Mariani S, Nikkhoo A (2020) Seismic reliability assessment of RC tunnelform structures with geometric irregularities using a combined system approach. Soil DynEarthqEng. https://doi.org/10.1016/j.soildyn.2020.106356

Mohsenian V, Mortezaei A (2018a) A new energy-absorbing system for seismic retrofitting of frame structures with slender braces. Bull EarthqEng 17(5):2715-2739

Mohsenian V, Mortezaei A (2018b) Evaluation of seismic reliability and multi-level response reduction factor ( $\mathrm{R}$ factor) for eccentric braced frames with vertical links. EarthqStruct 14(6):537-549

Mohsenian V, Nikkhoo A (2019) Evaluation of performance and seismic parameters of eccentrically braced frames equipped with dual vertical links. StructEngMech 69(6):591-605

Mohsenian V, Nikkhoo A, Hajirasouliha I (2019) Estimation of seismic response parameters and capacity of irregular tunnel-form buildings. Bull EarthqEng 17(9):5217-5239

Mortezaei A, Mohsenian V (2019) Reliability-based seismic assessment of multi-story box system buildings under the accidental torsion. J EarthqEng. https://doi.org/10.1080/13632469.2019.1692738

Nielson BG, DesRoches R (2007) Seismic fragility methodology for highway bridges using a component level approach. EarthqEngStructDyn 36(6):823-839

Nowak AS, Collins KR (2012) Reliability of structures. CRC Press, Boca Raton

PEER ground motion database, Pacific earthquake engineering research center, Web Site: http://peer.berke ley.edu/peer-ground-motion-database

Rahnavard R, Hassanipour A, Suleiman M, Mokhtati A (2017) Evaluation on eccentrically braced frame with single and double shear panels. J Build Eng 10:13-25

Sabouri-Ghomi S, Saadati B (2014) Numerical modeling of links behavior in eccentric bracings with dual vertical links. Numer Methods Civil Eng 1(1):14-20

Seki M, Katsumata H, Uchida H, Takeda T (1988) Study on earthquake response of two-storied steel frame with Y-shaped braces. Proceedings 9th world conference on earthquake engineering, Tokyo-Kyoto, Japan, pp. 65-70

Shayanfar MA, Barkhordari MA, Rezaeian AR (2011) Experimental study of cyclic behavior of composite vertical link in eccentrically braced frames. Steel Compos Struct 12(1):13-29

Shu Z, Ning B, Li S, Li Z, Gan Z, Xie Y (2020) Experimental and numerical investigations of replaceable moment-resisting viscoelastic damper for steel frames. J Constr Steel Res 170:106100

Vetr MG (1998) Seismic behavior, analysis and design of eccentrically braced frames with vertical shear links. Ph. D. thesis. University of technology Darmstadt w, Germany

Vetr MG, Ghamari A, Bouwkamp J (2017) Investigating the nonlinear behavior of eccentrically braced frame with vertical shear links (V-EBF). J Build Eng 10:47-59

Zahrai SM, Mahroozadeh Y (2010) Experimental study of using vertical link beam to improve seismic performance of steel buildings. J Civil SurvEng 44(3):379-393

Zahrai SM, MoslehiTabar A (2013) Analytical study on cyclic behavior of chevron braced frames with shear panel system considering post-yield deformation. Can J CivEng 40(7):633-643

Zahrai SM, Parsa A (2015) Effect of flange width of vertical link beam on cyclic behavior of chevron braced steel frames. J SeismolEarthqEng 17(4):281-292

Zareian F, Krawinkler H, Ibarra L, Lignos D (2010) Basic concepts and performance measures in prediction of collapse of buildings under earthquake ground motions. Struct Des Tall Spec Build 19:167-181

Publisher's Note Springer Nature remains neutral with regard to jurisdictional claims in published maps and institutional affiliations. 


\section{Affiliations}

\section{Vahid Mohsenian $^{1}$ (D) $\cdot$ Iman Hajirasouliha ${ }^{2}$ (D) $\cdot$ Reza Filizadeh $^{3}$ (D)}

1 Department of Civil Engineering, University of Science and Culture, Tehran, Iran

2 Department of Civil and Structural Engineering, The University of Sheffield, Sheffield, UK

3 Department of Civil Engineering, Sharif University of Technology, Tehran, Iran 